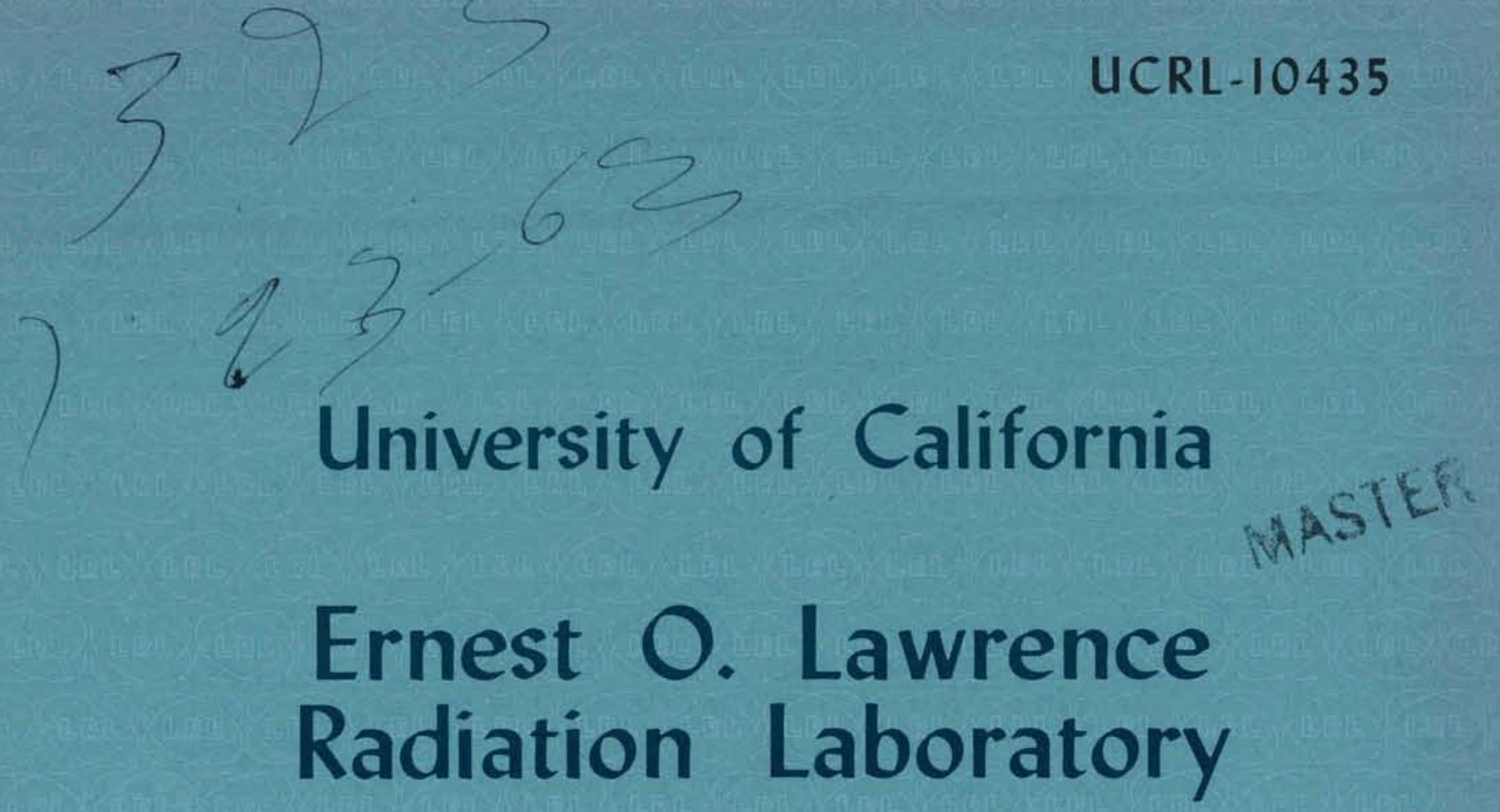

\title{
DEFORMATION AND FRACTURE OF POLYCRYSTALLINE LITHIUM FLUORIDE
}

Berkeley, California 


\section{DISCLAIMER}

This report was prepared as an account of work sponsored by an agency of the United States Government. Neither the United States Government nor any agency Thereof, nor any of their employees, makes any warranty, express or implied, or assumes any legal liability or responsibility for the accuracy, completeness, or usefulness of any information, apparatus, product, or process disclosed, or represents that its use would not infringe privately owned rights. Reference herein to any specific commercial product, process, or service by trade name, trademark, manufacturer, or otherwise does not necessarily constitute or imply its endorsement, recommendation, or favoring by the United States Government or any agency thereof. The views and opinions of authors expressed herein do not necessarily state or reflect those of the United States Government or any agency thereof. 


\section{DISCLAIMER}

Portions of this document may be illegible in electronic image products. Images are produced from the best available original document. 
UCRL- 1.0435

UC-25 Metals, Ceramics, and Materials TID-4500(17th Ed.)

\section{UNIVERSITY OF CALIFORNIA \\ Lawrence Radiation Laboratory Berkeley, California \\ Contract No. W-7405-eng-48}

DEFORMATION AND FRACTURE

OF POLYCRYSTALLINE LITFIUM - FLUORIDE

William D. Scott

(Ph.D. Thesis)

September 14, 1962 
Printed in USA. Price $\$ 2.00$. Available from the

office of Technical Services

U. S. Department of Commerce

Washington 25 , D.C. 
DEFORMATION AND FRACTURE

OF POLYCRYSTALLINE LITHIUM FLUORIDE: $\because$

\section{Contents}

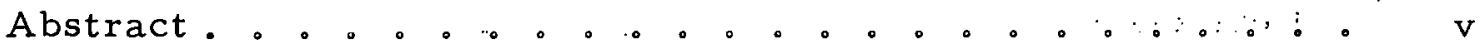

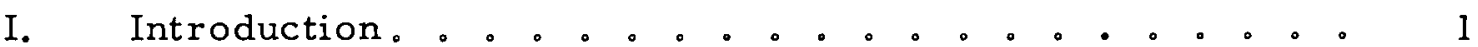

A. Properties of Lithium Fluoride Single Crystals 。 。 1

B. The Fracture of MgO Single Crystals . . . . . . 3

C. The Plasticity of Polycrystalline Aggregates . . . 3

D. Fracture of Polycrystalline Aggregates . . . . . 6

II. Experimental Procedure

A. LiF Purification and Single-Crystal Growth。 。 . 10

B. Polycrystal Formation . . . . . . . . . 12

C. Specimen Fabrication . . . . . . . . . . 14

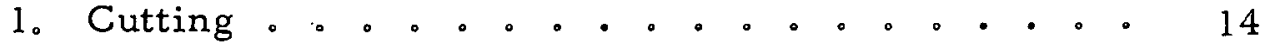

2. Polishing . . . . . . . . . . . . . . . 14

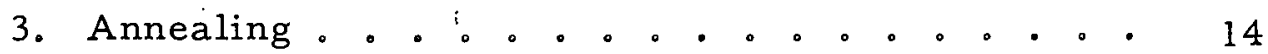

D. Bend Tests................... 16

1. Outer Fiber Strain . ........... 16

2. Outer Fiber Stress. . . . . . . . . . 18

E. Etching and Microscopic Examination . . . . . 19

III. Results

A. Etching . . . . . . . . . . . . . 20

B. Single-Crystal LiF。. 。. . . 。 。 . . . . . 24

1. Effect of Sample Treatment on Ductility. . . . 24

2. Crystal Orientation and Macroscopic Stress-

Strain Curves . . . . . . . . 30

C. Deformation of Polycrystalline LiF . . . ... . . 33

1. Macroscopic Stress-Strain Curves . . ... . 33

2. Observation on Etched Polycrystals . . . . . 33

D. Fracture of Polycrystalline LiF. . . . . . . . 58

1. Fracture through 3-Grain Junctions . . . . 58

2. Fracture in the Slip Plane......... 61 
IV. Discussion of Results

A. Plastic Flow and Fracture . . . . . . . . 64

B. Fracture in the Slip Plane . . . . ... 68

V. Summary and Conclusions ......... 72

Acknowledgments . . . . . . . . . . . 74

References . ................ 75 


\title{
DEFORMATION AND FRACTURE OF POLYCRYSTALLINE LITHIUM FLUORIDE \\ William D. Scott \\ Inorganic Materials Research Division \\ of Lawrence Radiation Laboratory \\ and Department of Mineral Technology, \\ University of California, Berkeley, California
}

September 14, 1962

\begin{abstract}
Techniques for forming polycrystalline LiF from the melt
\end{abstract} and for fabricating test specimens were developed and evaluated using single-crystal LiF as a control. Large-grain polycrystalline specimens tested in four-point loading always showed some plastic deformation $(0.076$ to $0.798 \%)$ before fracture, but the plastic flow was sharply reduced from that of single crystals. An etch was developed revealing dislocations on all crystallographic faces of LiF. Details of plastic deformation in polycrystalline material were investigated. Deformation was inhomogeneous among the grains of an aggregate because of differences in orientation with respect to the applied stress, and also within individual grains because of interactions between adjoining grains. Grain boundaries were barriers to slip, but stresses resulting from slip in one grain were transmitted to neighboring grains and often caused local deformation near the boundary. Because of local stresses, local slip systems operated although the resolved shear stresses on them from the applied load were below the critical yield stress. In one case, slip occurred on an (010) plane. Threegrain junctions were areas of high residual stress. Fractures originated at boundaries at or near 3-grain junctions, not as a result of inherent boundary weakness but rather because of high stresses developed at the boundary. A quantitative expression for fracture originating in a slip band was applied to one type of fracture. 


\section{INTRODUCTION}

Many extensive investigations have been directed toward elucidating the role of dislocations in the basic mechanisms of deformation and fracture. Information on the details of dislocation behavior has been obtained from studies on single crystals of metals and nonmetals in relatively simple states of stress. An understanding of dislocation behavior in single crystals is invaluable for an understanding of the mechanical properties of polycrystalline aggregates. However, because of the marked influence of grain boundaries and neighboring grains on plastic deformation and fracture, it is not possible at present to predict the mechanical properties of polycrystals from single-crystal data alone. This study of polycrystalline lithium fluoride was undertaken in an attempt to relate known properties of single-crystal Li $F$ to actual deformation and fracture characteristics of polycrystalline LiF。

In this report the details of plastic deformation and fracture in single-crystal $\mathrm{LiF}$ and other $\mathrm{NaCl}$ structures are first reviewed. This review is followed by a section describing reported observations on plastic deformation and fracture in metallic and nonmetallic polycrystalline aggregates. A description of the present experiments, the results obtained, and a discussion of these results in relation to dislocation and fracture mechanisms then follow.

\section{A. Properties of Lithium Fluoride Single Crystals}

Lithium fluoride has the $\mathrm{NaCl}$ structure and undergoes plastic deformation at room temperature on six slip systems of the type (110) [1 10$]$. Another possible slip system, $\{100\}\langle 110\rangle$, is not normally active at room temperature but does become active at higher temperatures. The stress necessary to cause slip on the $\{100\}\langle 110\rangle$ system in torsion at $400^{\circ} \mathrm{C}$ is about the same as the stress required for slip on the $\{110\}\langle 110\rangle$ system at room temperature ${ }^{l}$ Etching 
techniques that show the points of emergence of individual dislocations on $\{100\}$ type faces have been developed and used by Gilman and Johnston to reveal details of the role of dislocation mechanism in the plastic deformation of $\mathrm{LiF}^{2}$ Some of the results of various investigations on the mechanical properties of single-crystal LiF are summarized below:

(1) The stress necessary for homogeneous nucleation of dislocations in LiF is high, being about 1/30 uf the shcar modulus. Surface damage or small foreign hetcrogeneities cause most of the dis location nucleation in LiF crystals. 3

(2) A single dislocation loop expanding rapidly under an applied stress leaves a large number of new dislocations in its wake. These new dislocations also expand and multiply and a slip band is thus formed. 2 A cross-slip mechanism for this multiplication has been proposed by Johnston and Gilman. 4

(3) Johnston and Gilman have also stated that "The yield stress of $\mathrm{LiF}$ is determined by the stress required to move a dislocation in an otherwise dislocation-free region of the crystal. The yield stress is not influenced by the state of pinning or the geometrical arrangement of the [sessile, grown-in] dislocations in an as-grown crystal, and such dislocations do not take part in the deformation." 5

(4) Aging at $100^{\circ} \mathrm{C}$ tends to pin existing glide dislocations and to raise their resistance to motion. Once moving, however, they behave in the same manner as freshly introduced dislocations. 3 The resistance to the movement of fresh or unpinned dislocations is increased as the hardness of a particular crystal is increased. The hardness of a crystal of a given purity depends upon the thermal his tory of the crystal. Thus, crystals cooled at about $1^{\circ} \mathrm{C}$ per hour from $250^{\circ} \mathrm{C}$ are hard, while those that have been cooled from : . $250^{\circ} \mathrm{C}$ to room temperature in a few minutes are relatively soft. 5 Nadeau and Washburn found that the hardness of crystals quenched from $820^{\circ} \mathrm{C}$ is increased by annealing in the range 150 to $200{ }^{\circ} \mathrm{C} .6$ Annealing above about $325^{\circ} \mathrm{C}$, followed by an air quench to room temperature, softens the crystal. 
(5). Dislocation velocities are sensitive to applied stress, increasing very rapidly with increasing stress. Over a wide range of velocities, edge components move about 50 times as fast as screw components. The macroscopic yield drop, as observed in compression in a hardness testing machine, is a function of the deformation imposed by the machine in relation to the dislocation velocity and multiplication generated in the test specimen to accommodate this deformation. 5

(6) Reaction coatings (of $\mathrm{MgF}_{2}$ ), or plated metallic coatings, raise the yield stress of LiF by restricting the operation of surface dislocation sources and by preventing dislocation movement and multiplication. A surface coating can act as a stable barrier to dislocations that cause dislocation pile-up, coalescence, and formation of crack nuclei beneath the film. 7

\section{B. The Fracture of MgO Single Crystals}

Magnesium oxide has the same crystal structure as LiF and deforms plastically at room temperature on the same slip systems and in the same general manner as LiF. The fracture of MgO single crystals has been studied in some detail by Stokes, Johnston, and $\mathrm{Li}, 8,9,10,11$ and Washburn, Gorum, and Parker。 12 The intersection of a (110) [110] slip band with a (110)[1ㅣㅣ slip band has been found to nucleate a Stroh crack if one of the slip bands is blocked by the other. Stokes et al. have shown that the slip distribution in the crystal at the time of crack nucleation controls whether crack nucleation or crack propagation is the critical step in brittle failure. 11 Cracks nucleated with little slip propagate immediately and cause failure. However, if a large number of slip bands are present, the nucleated crack may be stabilized between two of them and plastic flow will continue.

\section{The Plasticity of Polycrystalline Aggregates}

It is difficult to use the experimental results obtained with single crystals for a quantitative prediction of the properties of polycrystals, because the crystals in a polycrystalline aggregate do not behave as individual single crystals. They are strongly influenced by 
their neighbors and by the necessity for maintaining boundary contact during plastic deformation.

Carpenter and Elam observed that, during tensile deformation of large-grained aluminum, neighboring crystals appeared: to:exert a supporting effect on each other. 13 Deformation at the boundary was less than that at the center of the crystals; this effect was noticeable 2 to $5 \mathrm{~mm}$ from the boundary。

Paxton et al. found that, in iron, no slip occuried within about 5 microns of the boundary. 14 Between 5 and $20 \mu$ from the boundary fine slip occurred, and this went to coarse slip beyond $20 \mu$ from the boundary.

Other investigations, however, have shown that deformation is often increased in the region of a boundary. Figure 1 gives some of the results of Boas and Hargreaves ${ }^{15}$ relative to the deformation of large-grain polycrystalline aluminum. It can be seen that there were wide differences in deformation from grain to grain. The geometry of the aggregate influenced the actual stress on the grain and the extent of its deformation. The deformation was also inhomogeneous within each grain; the grains deformed at their boundaries in a manner tending to accommodate the deformation of their neighbors. In this way, local slip only indirectly related to the applied stress can develop at grain boundaries.

According to Taylor, at least five independent operating slip systems are necessary to maintain boundary contact in a plastically deformed polycrystalline aggregate. ${ }^{16}$ LiF has only six slip systems that normally can be operative at room temperature, and it is unlikely that all of them, or even five of them, will always be suitably oriented for deformation under the applied stress. For this reason, the ductility of polycrystalline LiF should be strongly influenced by the limited number of slip elements available for deformation. Hexagonal metals such as zinc and magnesium also have a limited number of slip elements that are normally operative at room temperature. The ductility of hexagonal metals is much less than that of face-centered cubic metals, in 


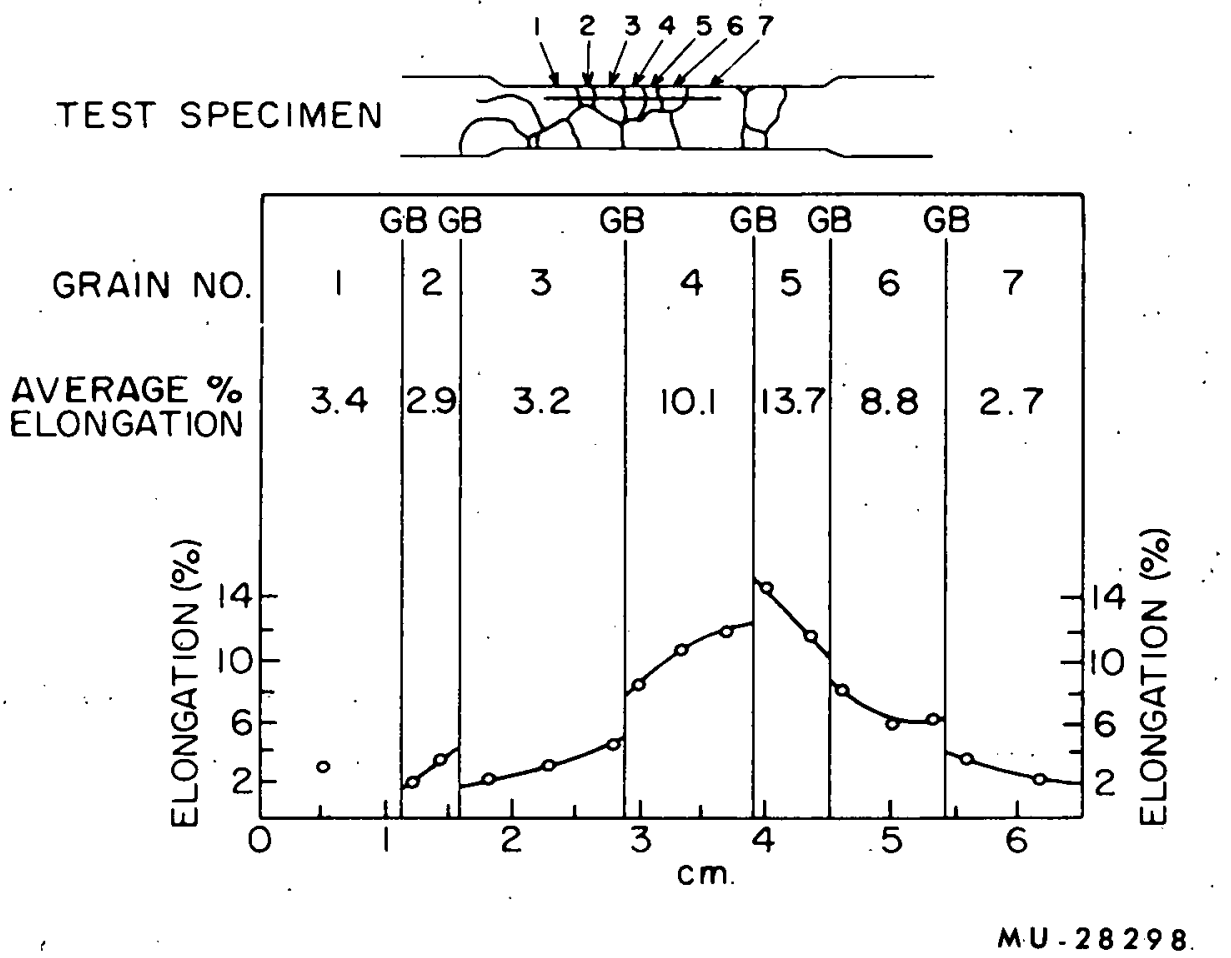

Fig. 1. Local deformation of the grains of an aggregate after $5 \%$ elongation of the test specimen (from Boas and Hargreaves, reference 15). 
which 12 slip systems are available, but they do show slight plastic deformation at room temperature. The question then arises as to how deformation is accommodated in these metals if Taylor's requirement is rigorously obeyed.

The deformation of bicrystals and polycrystals of hexagonal metals has been the subject of several investigations. Gilman, 17 investigating zinc bicrystals, and Mote and Dorn ${ }^{18}$ in a similar study on magnesium bicrystals, concluded that boundaries were barriers to dislocation movement. However, stresses resulting from this blocked slip were often relieved by local deformation in neighboring grains. Hauser et al. also found that local grain boundary deformation and grain boundary shear were common in polycrystalline magnesium. ${ }^{19,20}$ Thus, it appears that grain boundary contact is maintained by local deformation in the region of the boundary.

Information on deformation of polycrystalline $\mathrm{NaCl}$ structures is limited to silver chloride. Nye used polarized light to observe slip bands and stress concentrations in $\mathrm{AgCl}^{21} \mathrm{He}$ proposed the following process for polycrystalline deformation. When the critical resolved shear stress is reached on a particular grain, it slips. The slipped grain then exerts a nonhomogeneous stress on its neighbors. It is unlikely, however, that a slip plane in a neighboring grain will meet the operating plane in the first grain in a line in the boundary. Therefore, the boundary acts as a barrier and an internal stress in the neighboring grain is developed by slip in the first grain.

\section{Fracture of Polycrystalline Aggregates}

Gilman has pointed out that the fracture of a polycrystalline aggregate involves three distinct steps: the nucleation of a crack, the propagation of this crack in the crystal where it was nucleated and, finally, the propagation of the crack into a neighboring crystal. 22 Zener first suggested the idea that cracks could be nucleated by the coalescence of edge dislocations that are blocked in a slip band by some obstacle such as a grain boundary. 23 The theory as developed quantitatively by Stroh gives an atomistic description of the crack nucleation mechanism. ${ }^{24}$ Slip occurs first in the most favorably 
oriented grains and continues until dislocations pile up at a grain boundary. High local shear and tension stresses exist at the head of the pile up. This local stress is relieved if enough mechanisms of deformation become operative in the original and adjacent grain. If local deformation does not occur, pile-up will continue until a crack is nucleated.

Gilman found that blocked edge dislocations do initiate such fractures in zinc, but that the crack is nucleated in the slip plane 17 rather than perpendicular to it as suggested by Stroho ${ }^{24}$ In zinc, blocked screw dislocations are not effective in reducing fracture stress. In his study of the fracture of $\mathrm{MgO}$ bicrystals, Westwood also found that grain boundaries are effective barriers to slip. ${ }^{25}$ Dislocations pile up at the boundary, and fractures originate in the boundary at points where two slip lines from opposite sides of the boundary meet. The fractures move out of the boundary onto a cleavage plane as soor as they leave the fracture origin at the slip band.

Gilman has also discussed the possibility that crack propagation rather than crack nucleation is the critical step in brittle failüre. $^{22}$ Thus, the initiation of a Griffith crack by a dislocation nucle:ation mechanism may be relatively, easy, while the movement of the crack through areas that increase its energy (such as grain boundaries) is the more difficult step.

It will be shown later that three-grain junctions play an important role in the fracture of polycrystalline LiF。 The only discus sion of deformation and fracture at this type of junction has been in connection with grain boundary sliding in high-temperature creep. Zener pointed out that the relaxation of shear stress across any one grain boundary of a 3-grain junction will result in a stress concentration identical to that produced by the relaxation of shear stress across a crack. ${ }^{23}$ The result is an area of hydrostatic tension at the grain junction. Betteridge and Franklin discussed a slightly different configuration, in which shear across one boundary produced shear in the grain at the end of the boundary。 ${ }^{26}$ This situation, as pictured schematically by Cottrell, 27 is shown in Fig。2。 


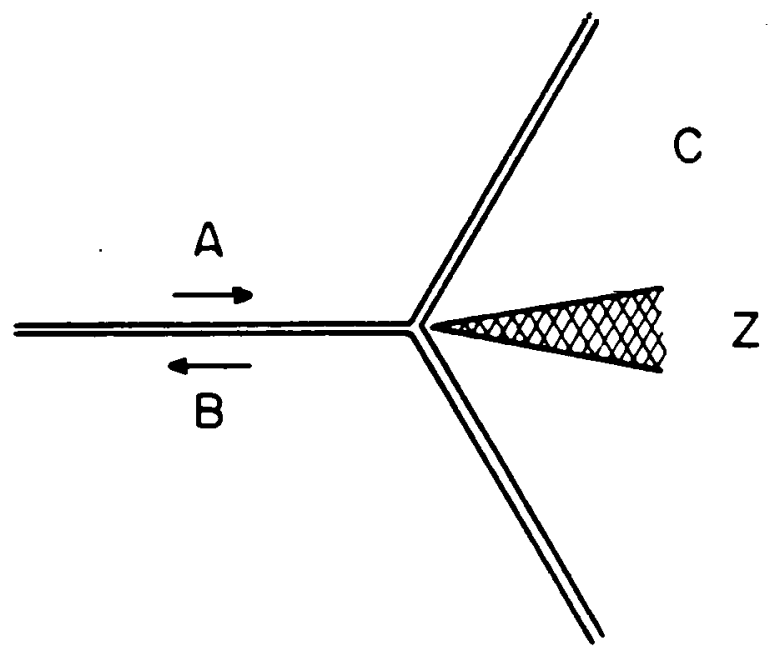

$M U-28299$

Fig. 2. Accommodation of a shear displacement along the boundary between grains $A$ and $B$ by plastic deformation in zone $Z$ of grain C (from Cottrell, reference 27). 
From the foregoing theories and observations, it is seen that the processes of deformation and fracture are interrelated. The interpretation of the fracture process is that deformation, or more precisely the blocking of deformation, is the mechanism that creates the very high local stresses necessary for the initiation of fracture. If these local stresses are not relieved by plastic deformation, they may initiate fracture by the nucleation of a Griffith crack. If the Griffith crack is not stabilized, either by striking an obstacle or by plastic flow at the crack tip, it will propagate and brittle failure will result。 


\section{EXPERIMENTAL PROCEDURE}

The plan of this work was first to obtain a quantity of uniform high-purity LiF. Cleaved single crystals of this material were then used as controls to evaluate techniques for cutting, polishing, and annealing LiF polycrystals. Polycrystalline specimens were prepared from this same material and tested in bending. An etch was developed which showed dislocation slip bands on all crystallographic faces of LiF. Through the use of this etch, the observed macromechanical properties were related to the microstructures and microdeformation of the polycrystalline specimens.

\section{A. LiF Purification and Single-Crystal Growth}

Lithium fluoride was purified by a modified Bridgman normal freezing method. A diagram of the vacuum resistance furnace is shown in Fig. 3. The furnace core was 2-1/2-in。-i。d., 30-in。-long al umina。 It was externally wound with Kanthal. A-1 wire on the center 10 inches. Power was supplied by a $5-\mathrm{kW}$ saturable reactor, and the temperature was controlled by a Leeds and Northrup CAT controller. A Pt$\mathrm{Pt}-1 \% \% \mathrm{Rh}$ temperature control thermocouple was placed outside'the core against the center winding, and four Chromel-Alumel monitoring thermocouples were placed inside the core along the hot zone. The pressure at $900^{\circ} \mathrm{C}$ was $1 \times 10^{-4} \mathrm{~mm} \mathrm{Hg}$ 。

When alumina thermocouple tubing was in contact with the inside or outside of the furnace core, there was electrical leakage from the winding through the alumina insulators to the thermocouple. This electrical leakage became noticeable above $700{ }^{\circ} \mathrm{C}$ and caused the thermocouple to float at 60 volts ac above ground; erroneous temperature readings, as high as $40^{\circ} \mathrm{C}$, were then indicated by electronic potentiometer instruments. To eliminate this error, the inside ChromelAlumel thermocouples were made with $\mathrm{MgO}$-insulated, inconel-clad thermocouple stock. The thermocouple junctions did not touch the furnace wall and the Inconel sheathes were grounded. The exterior Pt $-\mathrm{Pt}$ $10 \%-\mathrm{Rh}$ control thermocouple, which was in contact with the furnace 


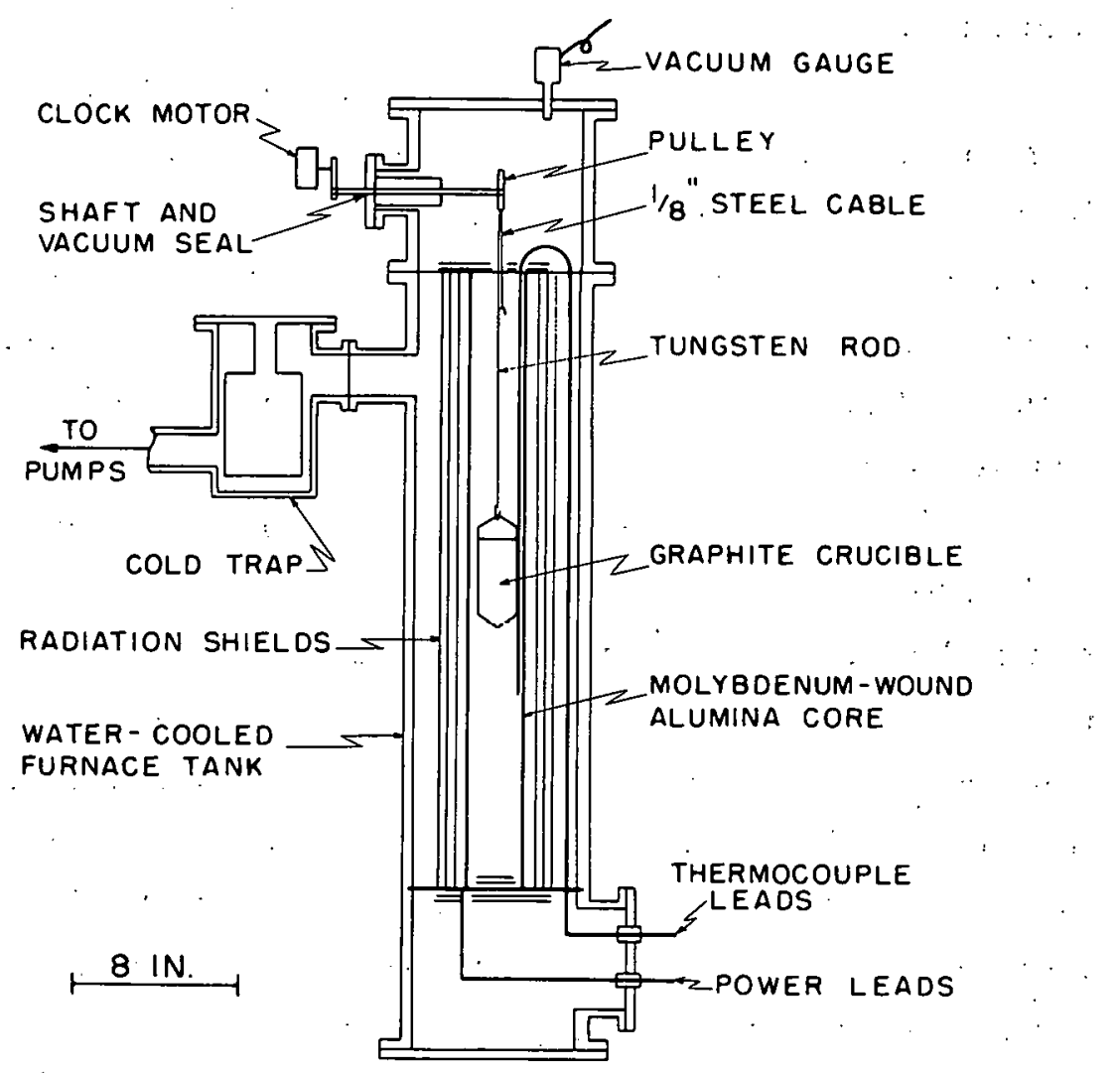

MU 26045

Fig. 3. Diagram of vacuum furnace used for purification of materials and single-crystal growth. 
winding, was insulated with boron nitride, as shown in.Fig. 4. This mounting eliminated all electrical pickup and gave highly responsive temperature control. The temperature inside the core was held constant to $\pm 0.2{ }^{\circ} \mathrm{C}$ at $900^{\circ} \mathrm{C}$.

The graphite crucible was 2 in. o.d. and 4.5 in. high, with 1/8-in. walls. It had a cone with an angle of about $130 \mathrm{deg}$ at the bottom. No corrosion of the crucible or furnace parts by LiF was observed over several hundred hours of operation. Because $\mathrm{Li} F$ vaporizes as a molecule, 28 no fluorine gas was present. Also, because of the vacuum, water vapor was not present to react with the $\mathrm{LiF}$ to form $\mathrm{Li}_{2} \mathrm{O}$ and $\mathrm{HF}$.

The starting material was Baker Analyzed Reagent grade LiF of 99.6 to $99.96 \%$ purity. Normal freezing purification was obtained by first melting the entire crucible charge and then lowering the crucible out of the hot zone at $1 / 4$ in. per hour. Impurities that lowered the freezing point of LiF were concentrated in the center of the ingot. The clear material broken out of the ingot then served as the next charge and the process was repeated. Four such treatments were necessary to obtain ingots that were completely clear. Twelve hundred grams of uniform, high-purity material was prepared in this way and several single crystals were obtained in the fourth-pass freezing。

\section{B. Polycrystal Formation}

Polycrystalline ingots were formed by lowering a rectangular flat-bottomed graphite crucible containing molten LiF out of the hot zone of the furnace. The crucible dimensions were 2 in, long by 2 in high, and 3/8-in, wide with 1/16-in. walls. The grain size was varied by lowering the crucible at rates ranging 1 to $96 \mathrm{in}$ 。/hr。 LiF has high thermal expansion and low thermal conductivity and is, therefore, sensitive to thermal shock. The minimum grain size obtained with the rather moderate quenches used in this study was about $3 \mathrm{~mm}$. 


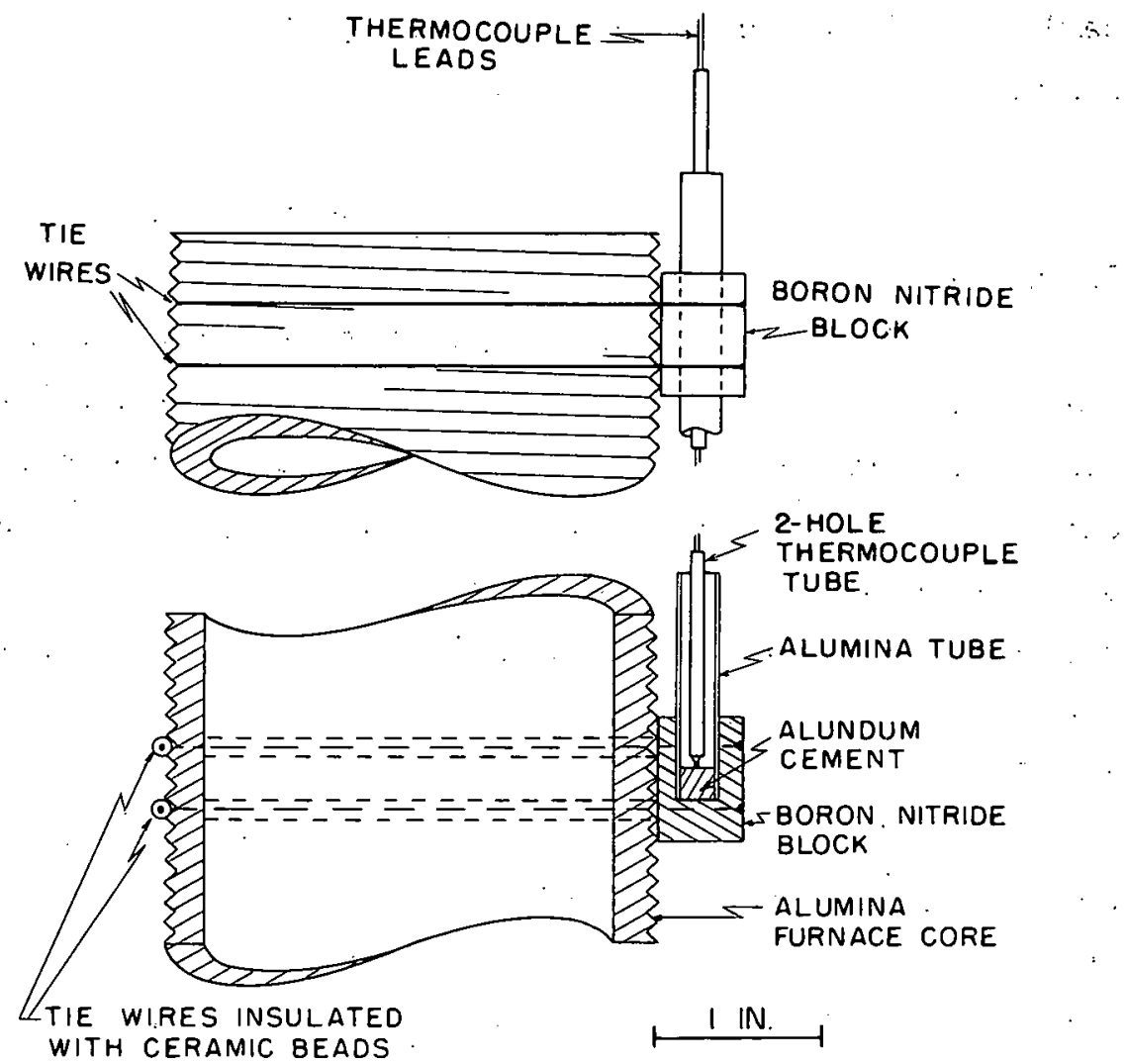

$M U .26046$

Fig. 4. Detail of the boron nitride mounting for the temperature control thermocouple. 
Crystallization started at the bottom and sides of the crucible. Because of the volume contraction of LiF when it freezes, the upper parts of the ingots contained large voids. Only. the bottom 1/8 in. of each 1 -in.-high ingot was used to prepare a polycrystalline test specimen.

\section{Specimen Fabrication}

\section{Cutting}

A polycrystalline ingot was cemented to a bakelite plastic slab with Dekhotinsky cement. One test specimen 2 in。 $\times 3 / 8$ in. $\times 1 / 8$ in. thick was then cut from the bottom of the ingot with a diamond saw using a smooth abrasive blade cooled by tap water. Single-crystal specimens were prepared either by cleaving or by cutting in the same manner as polycrystalline specimens. The cement was removed from the specimens with ethyl alcohol.

2. Polishing

Surface damage was removed from cut polycrystil specimens by polishing 6 to 12 hours in $200 \mathrm{cc}$ of hot $\left(60\right.$ to $\left.120^{\circ} \mathrm{C}\right)$ concentrated phosphoric acid. The specimens were cooled in the acid. They were then rinsed in,water, ethyl alcohol, and anhydrous ether. About 0.01 to 0.02 in. was removed from each surface. This polish was slightly selective in its attack on different crystallographic faces, but stirring the solution or rotating the specimen aided the attainment of a smooth, uniform surface. Single-crystal specimens were polished in a $2 \%$ $\mathrm{NH}_{4} \mathrm{OH}$ solution, as described by Gilman and Johnston。

3. Annealing

Specimens were annealed in vacuum in the same furnace described in Sec. II-A. They were placed in a vertical position in a graphite rack in a covered graphite crucible, with only the ends of the specimens in contact with the graphite. The anneal schedule consisted of heating to $810^{\circ} \mathrm{C}$ in . $2-1 / 2$ hours, soaking for 2 hours, and then cooling to room temperature in $4-1 / 2$ hours, as shown in Fig. 5 . 


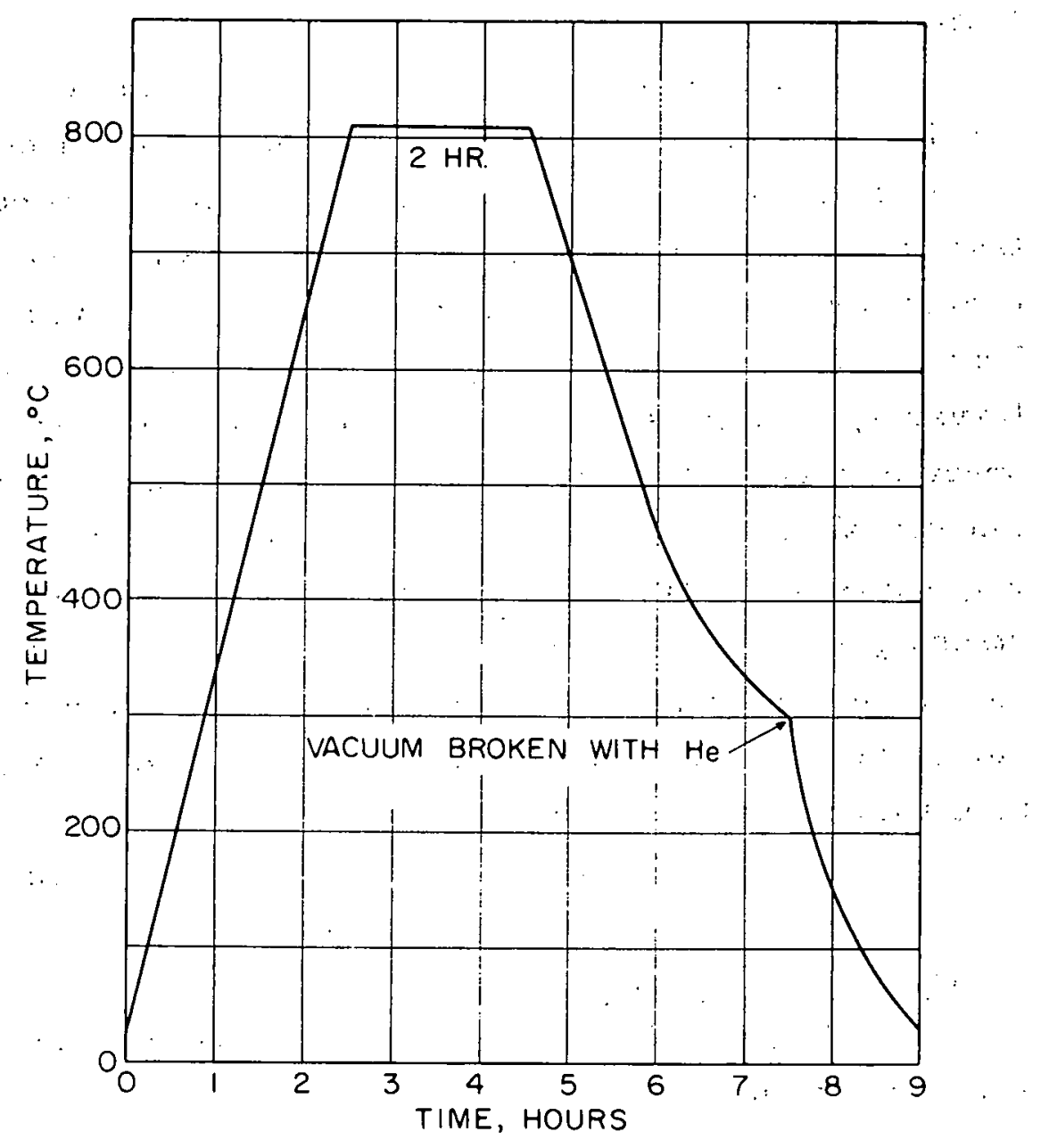

MU. 28300

Fig. 5. Anneal schedule used for LiF test specimens. 


\section{Bend Tests}

Bend tests were carried out in four-point loading with an Instron testing machine. A schematic diagram of the loading $j i g$ is shown in Fig. 6. The crosshead travel rate was $0.005 \mathrm{in} . / \mathrm{min}$ in all tests.

Bend tests have two major limitations in their usefulness for the measurement of mechanical properties of ductile materials. First, true stress-strain behavior cannot be evaluated from bend tests without having accurate tensile and compressive stress-strain curves for the material under test. Secondly, stress is not uniform but varies in intensity and sign across the thickness of the specimen. However, bend tests have several advantages besides the fact that the specimens are relatively easy to fabricate and to mount for testing. Because the maximum stress is at the outer fiber, fracture usually originates at, or near, the exterior tension surface. Because of the stress gradient across the specimen, the fracture sometimes propagates slowly, and the test can be stopped before complete failure occurs. Furthermore, bend specimens usually exhibit greater ductility than similar tension specimens.

In order to compare the stress-strain behavior of specimens tested in this study, the following methods of calculation were adopted. 1. Outer Fiber Strain

In general, the unit strain $\epsilon_{\mathrm{m}}$ at the outer fiber of a beam subjected to pure bending is

$$
\epsilon_{\mathrm{m}}=\mathrm{h} / 2 \mathrm{r}
$$

where $h$ is the thickness of the beam, and $r$ is the radius of curvature of the neutral axis. 29,30 This relationship assumes uniform deformation and identical stress-strain curves in tension and compression. In this study, the beam was assumed to bend in an elastic arc of uniform radius between the beam supports. From the geometry of a circle it follows that 

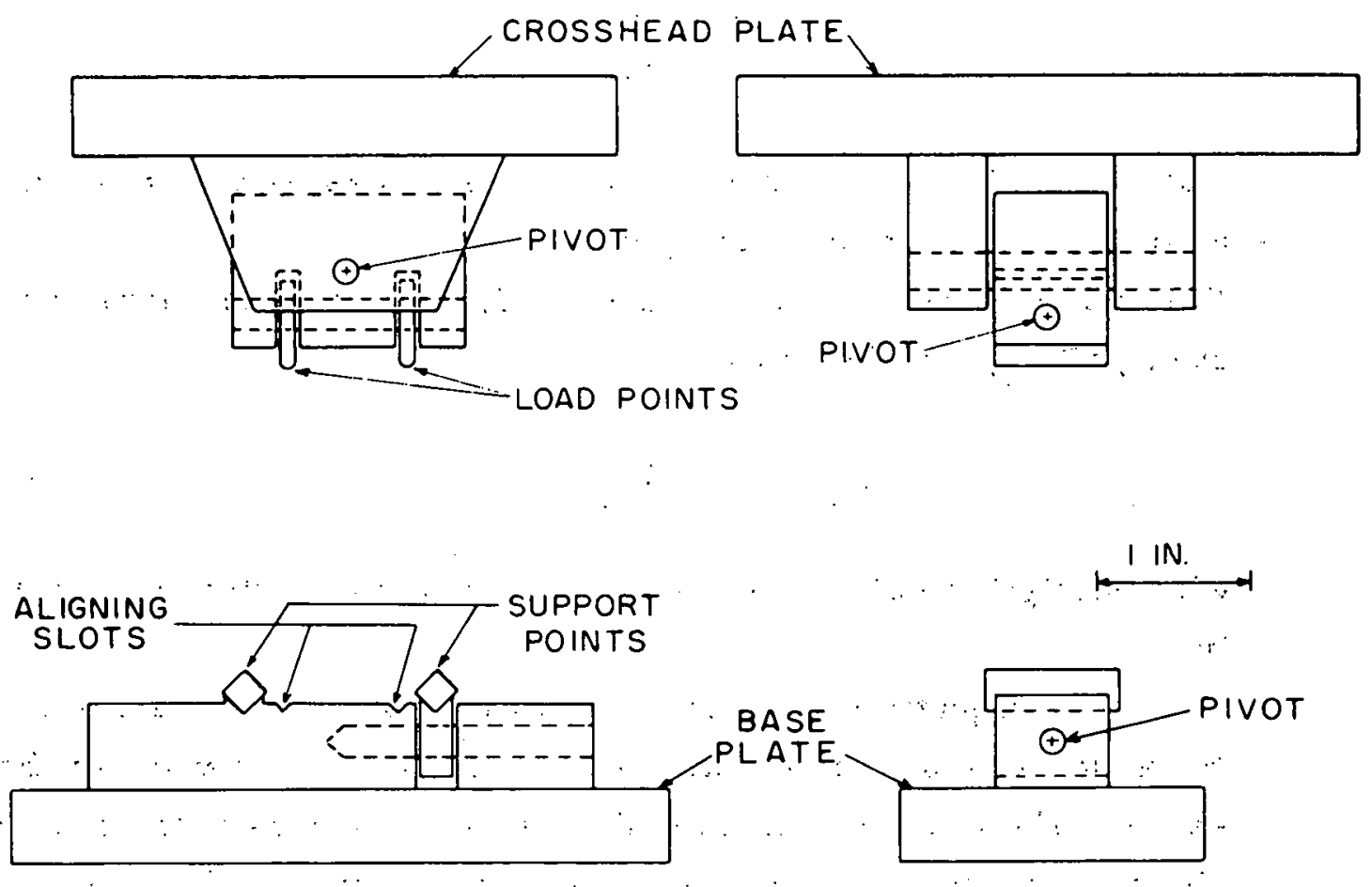

MU - 28302

Fig. 6. Schematic diagram of loading apparatus. 


$$
r=\left[\left(\frac{B+\Delta^{2}}{2 \Delta}\right)^{2}+\frac{L^{2}}{4}\right]^{1 / 2},
$$

where

$$
B=\left[\left(a-\frac{L}{2}\right)^{2}-\frac{L^{2}}{4}\right],
$$

and $\Delta=$ deflection at the load points as measured, a $=$ the moment arm, and $L=$ the support span length.

For the 1.25-in. support span and 1/4-in. moment arm used in this study, Eq. (1) reduces to

$$
\epsilon_{\mathrm{m}}=4 \cdot \Delta \cdot \mathrm{h}
$$

with negligible calculation errors on machine deflections up to 0.015 in.

Equation. (2) places a lower limit on outer fiber strain, Because of plastic deformation, the radius of curvature of the central section of the beam was actually less than that calculated in Eq. (2). Measurements made from enlarged photographs of heavily deformed single-crystal specimens gave plastic strains of 3 and $4 \%$ while the calculated $\epsilon_{\mathrm{m}}$ were 2.2 and $2.8 \%$, respectively. Although the error is large at large strains, it is much less for the small strains 10.2 to $0.8 \%$ ) calculated for polycrystalline specimens. Strains calculated using Eqs. (1) and (2) are called "Calculated Outer Fiber Strains" in the following discussion.

\section{Outer Fiber Stress}

Outer fiber stress was calculated also assuming elastic behavior. The equation used was

$$
\sigma_{\mathrm{m}}=\mathrm{Mc} / \mathrm{I} \text {, }
$$


where $\sigma_{m}=$ maximum outer fiber stress, $M=$ moment in the central section, $c=$ half the depth of the rectangular section, and $I=$ moment of inertia.

I. is given by

$$
I=\mathrm{bh}^{3} / 12
$$

where $b$ is the width and $h$ is the thickness of the beam. Equation (5) gives the upper limit of outer fiber stress, and this value is called "Calculated Outer Fiber Stress" in the following discussion.

E. Etching and Microscopic Examination

Polycrystalline specimens were etched after testing in a solution of $4 \% \mathrm{HBF}_{4}$ (Baker and Adamson fluoboric acid, 48-50\%, Purified) in 190- or 200- proof ethyl alcohol. The crystal was allowed to rest in the solution without agitation or stirring. The action of the etch depended on the concentration of acid and solution products. Fifty cc of solution was used for each crystal, and the etching time varied from 0.5 hour for small single crystals $(1 / 8 \times 1 / 8 \times 1$ in。 $)$ to 1.5 hours for large polycrystals $(3 / 8 \times 1 / 8 \times 2$ in. ). An evaluation of the reliability of the etch is described in Section III- $\dot{A}$.

Crystals were examined microscopically by reflected light with a metallograph and by transmitted light with a petrographic microscope. The light transmission of polycrystals was improved if they were polished for 1 minute in Gilman and Johnston's etch $\mathrm{A}^{2}$ either before or after etching in the $\mathrm{HBF}_{4}$ solution. The index of refraction of $\mathrm{LiF}$ at $1 \mu$ is $1.38711 .{ }^{31}$ The use of $\mathrm{n}$-butyl alcohol (index of refraction, 1.399) as an immersion medium facilitated transmitted-light examination of the specimens by obliterating the lower specimen surface that was out of focus. Photographs were taken with transmitted light, using a $32-\mathrm{mm}$ or $48-\mathrm{mm}$ lens for $10 \times$ or $5 \times$ magnification, and a petrographic microscope for higher magnifications. 


\section{III。 RESULTS}

\section{A. Etching}

The reliability of the $4 \% \mathrm{HBF}_{4}$ etch used in this study was established by comparing its ability to show up dislocation pits on a (100) face with Gilman and Johnston's etch A. ${ }^{2}$ These authors have shown that the latter etch reveals both fresh and aged dislocations on $\{100\}$ faces of LiF. Figure $7(a)$ shows a (100) face ot a lightlÿ deformed LiF crystal which was etched in etch A. The diagonal lines are edge bands, and the horizontal lines are screw, bands. This crys tal was chemically polished (in $2 \% \mathrm{NH}_{4} \mathrm{OH}$ ) until it was smooth, and then re-etched in $4 \% \mathrm{HBF}_{4}{ }^{\circ}$. Figure $7(\mathrm{~b})$ is a photograph of the same area after the second etch, and it shows that the same slip bands were etched in both cases. The same results were obtained when the sequence of etching was reversed. The screw bands were going into the crystal on a plane at $45 \mathrm{deg}$ to the plane of the photograph. They were displaced in Fig. 7(b) by an amount equal to the depth of (100) surface removed by the chemical polish. The center screw band in Fig. 7(b) appears to split because the surface was not a perfectly flat (100) face. The subboundary at the right edge of $7(a)$ was not etched in $7(b)$. Some subboundaries were etched by the $\mathrm{HBF}_{4}$ etch and others were not; the reasons for this selectivity are unknown.

Figure $8(a)$ is an enlarged view of the junction at the arrow in Fig. 7(a). The pits show the regular pyramid shape characteristic of Gilman and Johnston's etch A. Figure $8(\mathrm{~b})$ is the same junction etched with $4 \% \mathrm{HBF}_{4}$. The $\mathrm{HBF}_{4}$ etch produced pits that were less regular and less sharply defined than the pits produced by etch $A$, but the general features of the etched bands were the same in both cases.

Figure $9(a)$ shows slip bands on a (001) face that were etched with $4 \% \mathrm{HBF}_{4}$, and Fig. $9(\mathrm{~b})$ is the (110) face of the same crystal. They show that the slip lines etched on (001) were also etched on (110). A rather large misorientation across the subboundary on (110) can be seen by looking along the slip lines in Fig. 9.(b). This crystal 


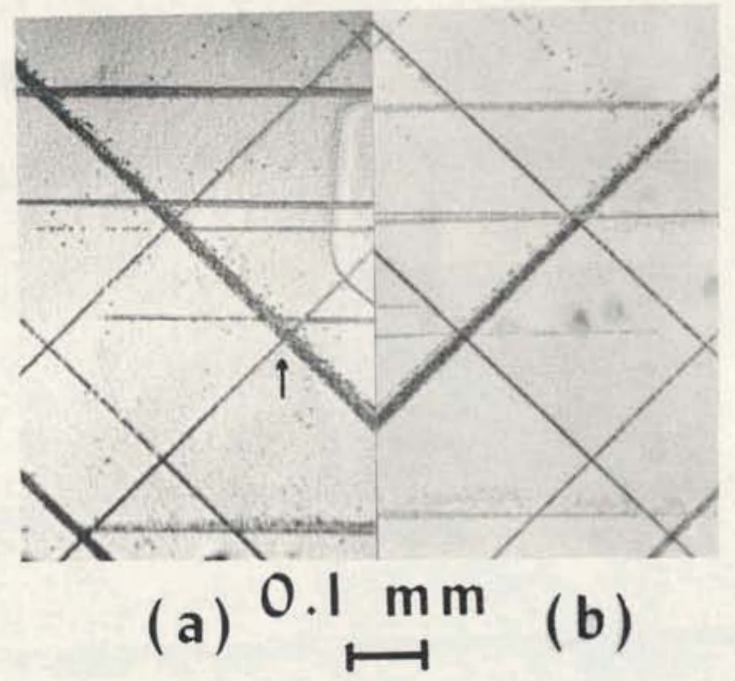

$\mathrm{ZN}-3345$

Fig. 7(a). Slip bands etched by Gilman and Johnston's etch A on a (100) face. Reflected light.

(b). Same area, polished and then etched in $4 \% \mathrm{HBF}_{4}$. Film reversed in printing. Transmitted light, $73 \mathrm{X}$. 


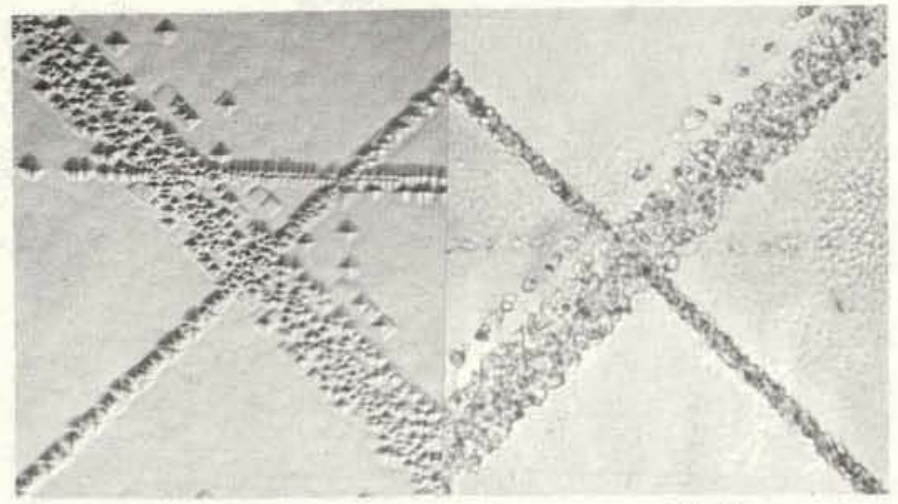

(a) $0.05 \mathrm{~mm}$ (b)

$\mathrm{ZN}-3347$

Fig. 8(a). Etch pits from etch A. This junction is indicated by the arrow in Fig. 7(a). Reflected light.

(b) Same junction, $\mathrm{HBF}_{4}$ etch. Film reversed in printing. Transmitted light, 400X. 


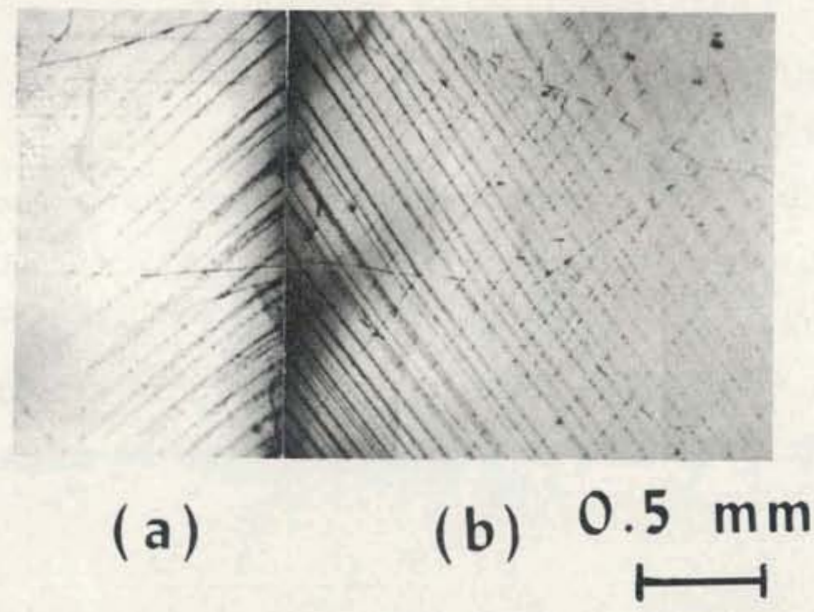

ZN-3348

Fig. 9. $4 \% \mathrm{HBF}_{4}$ etch on two crystallographic faces.

(a). Slip lines on a (001) face.

(b). Slip lines on an adjoining (110) face. Transmitted light, $23 \mathrm{X}$. 
was cut on a diamond saw, chemically polished, annealed, and deformed in bending.

A single crystal of LiF was deformed in compression. One end of the crystal was then ground into the shape of a hemisphere, chemically polished, and etched in $\mathrm{HBF}_{4}$. Figure 9(c) is a picture of the hemispherical end taken looking down the (001) compression axis of the crystal. It may be seen from the figure that the etch is equally effective on all crystallographic planes.

The effectiveness of $\mathrm{HBF}_{4}$ as an etchant is further illustrated by its effect on polycrystalline specimens. The orientations of several individual grains in some of the polycrystalline specimens, all of which were etched, were obtained from Laue x-ray back-reflection pictures. The positions of the poles of the planes of these grains which were in the tension or compression surface of the polycrystalline specimen are shown in Fig, 10. This figure also shows that there was a random orientation of grains in the polycrystalline aggregates.

\section{B. Single-Crystal LiF}

The single crystals used in this study were obtained from the purified material described in Section II-A. 1. Effect of Sample Treatment on Ductility

Figure 11 is a replot of the Instron load-deflection curve which shows the loading characteristics of the four-point bending apparatus used in this study. A machine offset of about $0.0005 \mathrm{in}$. occurs at about 0.25 pound. Figure 11 also shows in detail the slight amount of plastic flow that preceded fracture in as-cut single-crystal LiF.

Typical stress-strain curves for single crystals of LiF are shown in Fig. 12. (Stress-strain refers to calculated outer fiber stress and calculated outer fiber strain as explained in Sec.II-D-2.) The cut samples were prepared by cutting with a diamond saw along four $\{100\}$ cleavage planes. The cutting introduced considerable surface damage; the as-cut specimens were relatively brittle. However, as-cut specimens always underwent a small amount of plastic deformation before fracture. This behavior is consistent with two possible mechanisms 


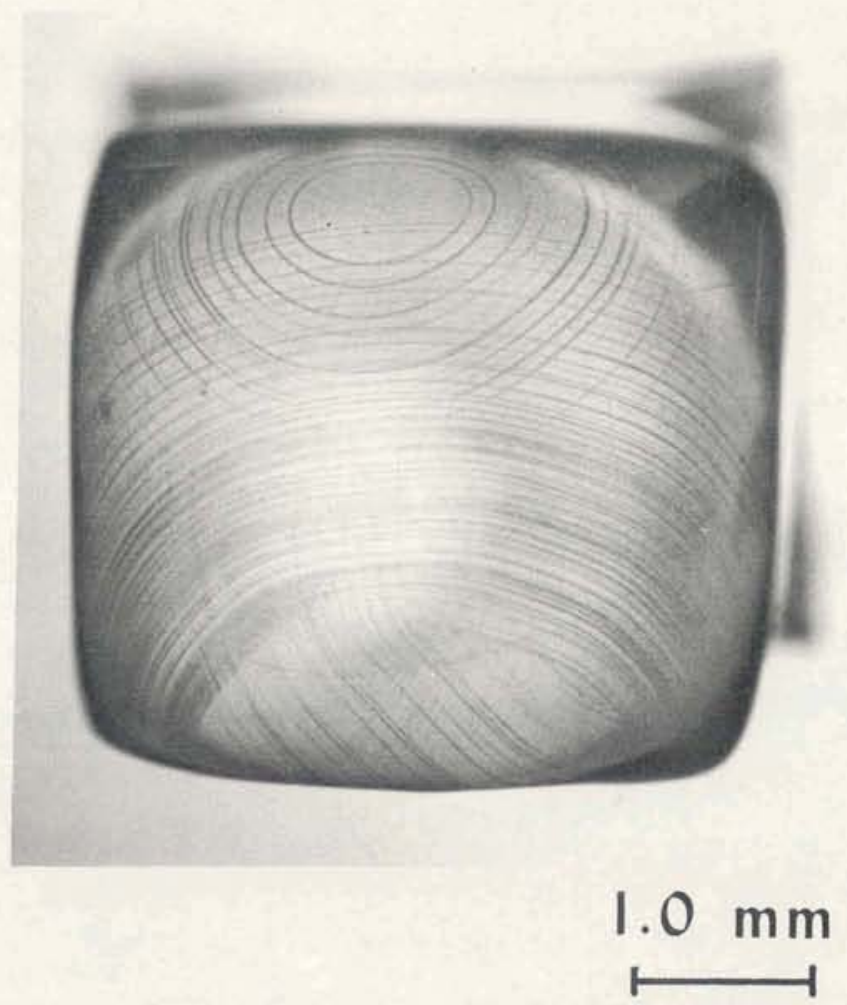

$\mathrm{ZN}-3349$

Fig. 9(c). Slip lines on a single crystal deformed in compression. $4 \% \mathrm{HBF}_{4}$ etch. Photograph is in $<100\rangle$ directions. Transmitted light, 10X. 


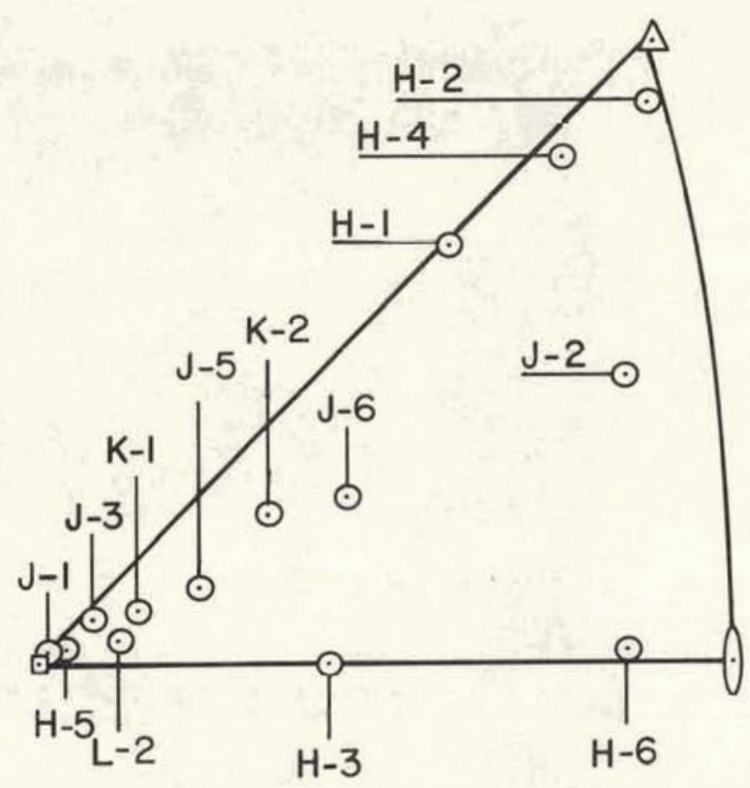

MU. 28198

Fig. 10. Stereographic triangle, showing the orientation of individual grains in polycrystalline specimens. 


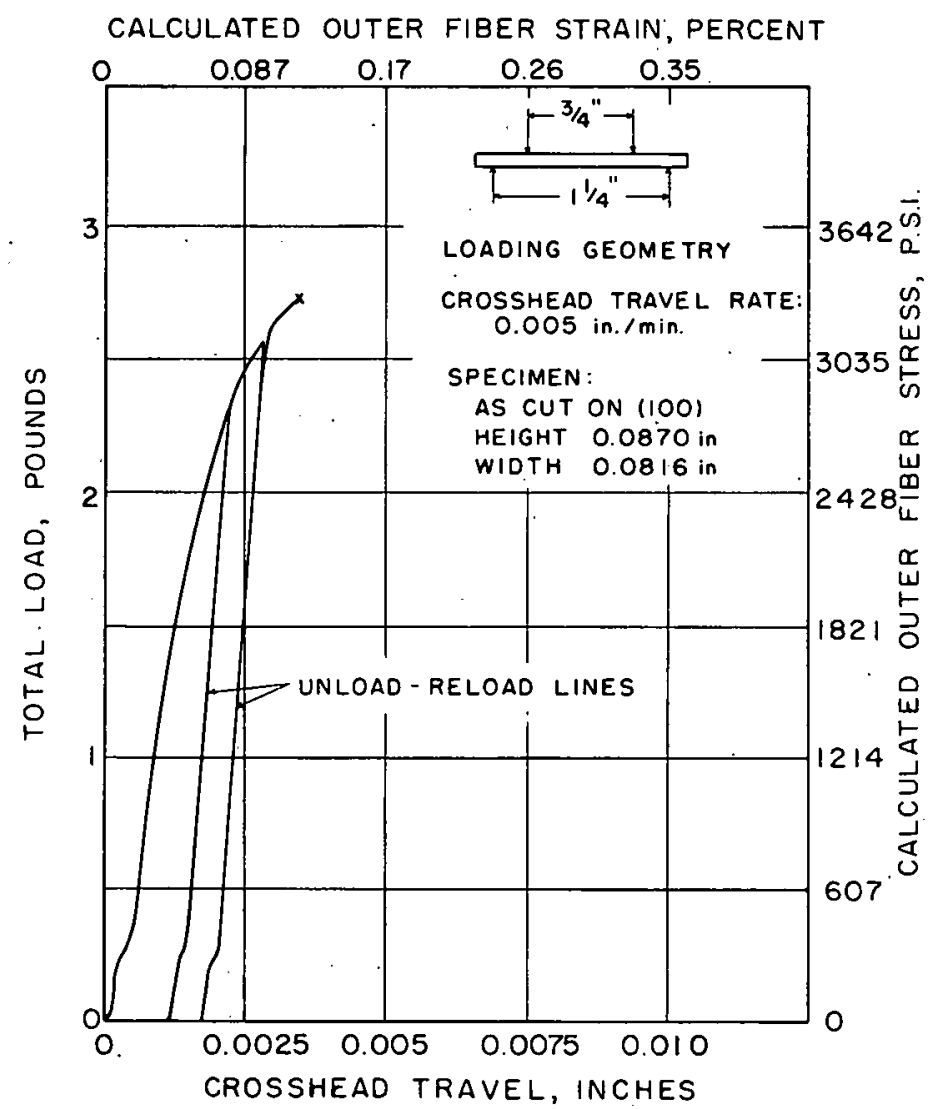

Fig. 11. Plasticity in as-cut single-crvstal LiF. 


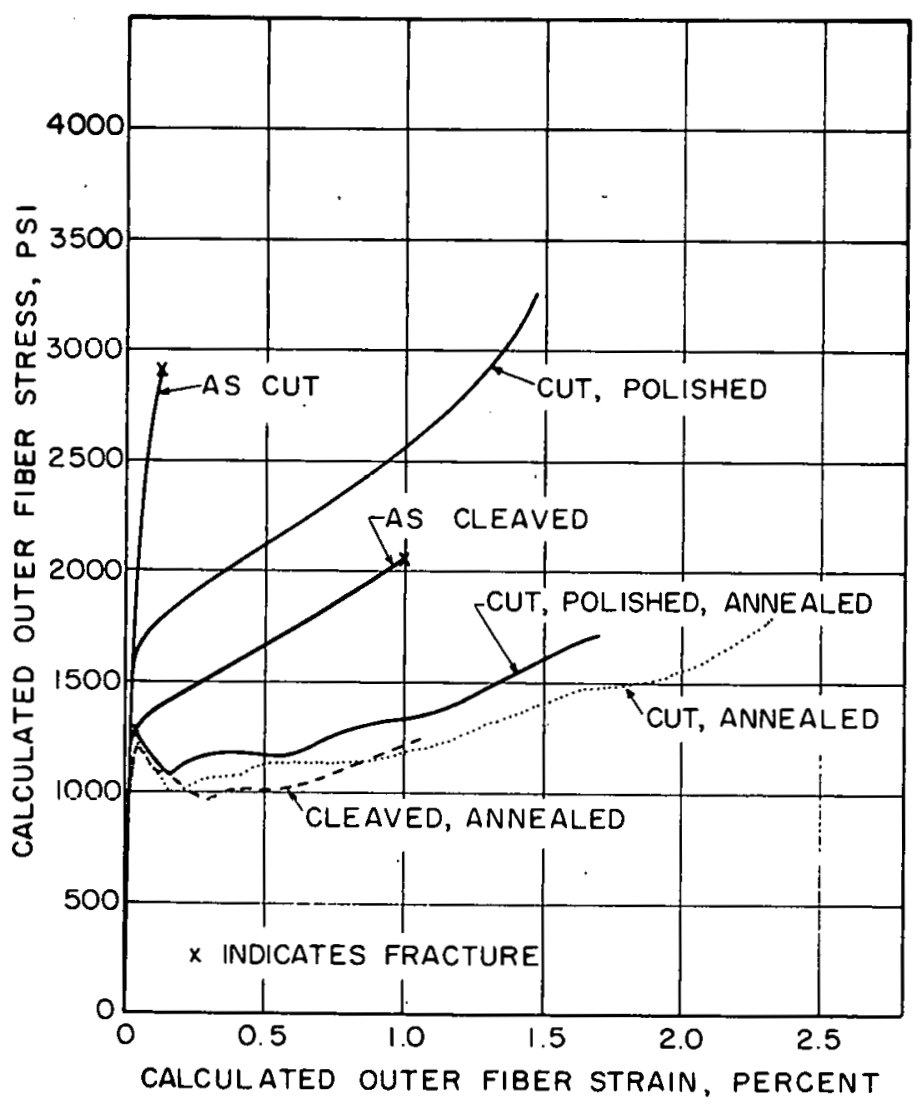

$M U-28165$

Fig. 12. Typical stress-strain curves for single crystal LiF. 
for failure."Failure was caused either by the propagation of cracks introduced by the sawing in which case plastic flow was merely incidental to the failure, or by cracks nucleated by the plastic flow. The second mechanism is believed to be the correct one for the following reasons:

(1) The fracture strength was always high (av。2980; range 2550 through 3340 psi), whereas a flaw mechanism would be expected to give a few relatively weak samples.

(2) It has been observed that large cracks were not altered by annealing, but in every case the ductility of cut specimens was restored by annealing.

(3) There was an obvious interference to dislocation motion, as evidenced by the small amount of plastic flow that occurred at high stresses.

The postulated fracture mechanism is that the damaged surface acted as a work-hardened layer which was a barrier to dislocation movement. This surface layer then had an embrittling effect similar to the coatings investigated by Westwood, ${ }^{7}$ in which fracture was nucleated by dislocation pile-up under the surface layer. Removing the damaged surface layer with a chemical polish restored the ductility, as shown in Fig. 12 .

It has been shown that a low-temperature anneal hardens $\mathrm{LiF}$ single crystals. 5,6 The cut-polished and as-cleaved specimens in Fig. 12 came from slowly cooled single-crystal material. In addition, the cut specimens were heated to about $135^{\circ} \mathrm{C}$ for 1 hour while they were being cemented to and removed from the sawing supports. The relatively high yield and work hardening of cut-polished specimens, and the similar work hardening of as-cleaved specimens, may be attributed to increased hardness of these crystals。" A high-temperature anneal reduced the yield and work hardening of these crystals to values similar to those for cut-annealed specimens

Thus, our experiments show that different forming methods and heat treatments can introduce large variations in the mechanical behavior of otherwise similar single crystals of LiF. However, after a 
suitable high-temperature anneal, all specimens, both cut and cleaved, exhibited similar yield points and ductility. The technique that was then adopted for the preparation of polycrystalline specimens consisted of cutting, followed by chemical polishing and a high-temperature anneal as described in Section II-C.

\section{Crystal Orientation and Macroscopic Stress-Strain Curves}

Figure 13 shows stress-strain curves for: crystals with three different orientations. The stereographic projection in the tigure shows the location of the specimen axis and the normal to the tension and compression surfaces. Crystal A was cut with the same orientation as the usual cleaved specimens, and $B$ was cut with the side face (100) and the top and bottom faces (01i). Specimen $C$ was oriented with its axis close to the [ï11] direction. A and $B$ were cut and annealed, and crystal $C$ was cut and chemically polished but not annealed.

There were large differences in the macroscopic stressstrain curves of the three crystals. However; it can be shown as an approximation that the resolved-stress vs. strain curves were not as different as Fig. 13 indicates. For this approximation, the calculated outer fiber stress $\sigma_{\mathrm{m}}$ was resolved into the slip plane and slip direction by the usual formula

$$
\tau=\sigma_{\mathrm{m}} \cos \lambda \cos \theta
$$

where $\tau$ is the resolved shear stress. The angle between the tension axis (taken here as the specimen axis) and the normal to slip plane is $\lambda$; the angle between the tension axis and the slip direction is $\theta$. The resolved-stress vs strain curves are given in Fig. 14. The maximum difference in stress between $A$ and $B$ is thus reduced from 1900 psi to $200 \mathrm{psi}$, and the maximum difference between $A$ and $C^{\prime}$ is reduced from 9600 to 950 psi. The yield stress was taken as the point where the stress-strain curve first deviated from a straight line. The average calculated outer fiber yield stress for five samples with orientation A was 1180 psi, and the average for four samples with orientation $B$ was 2590 psi. The average critical resolved shear stress for these two 


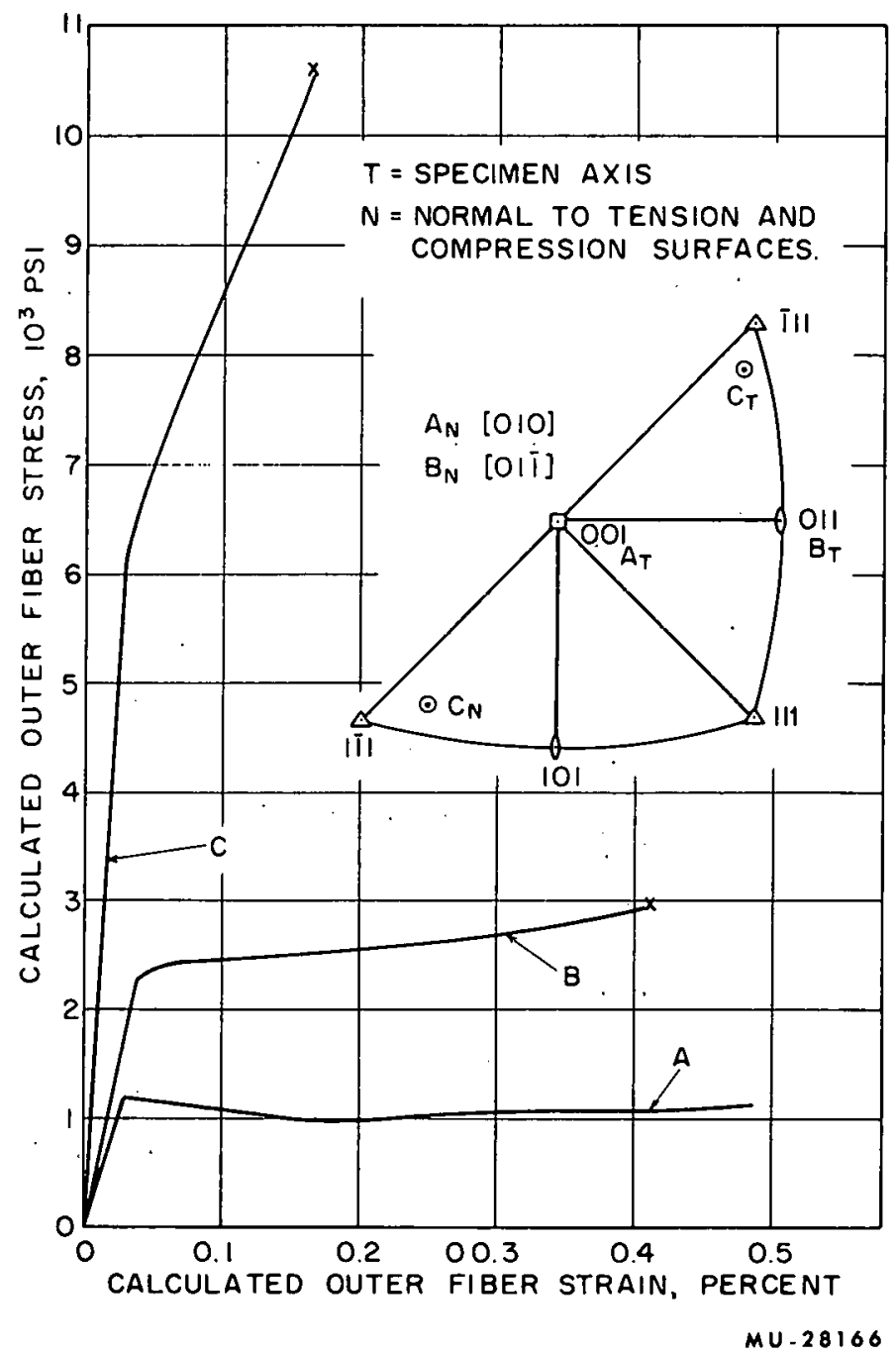

Fig. 13. Stress-strain curves in bending for LiF single crystals of different orientations. 


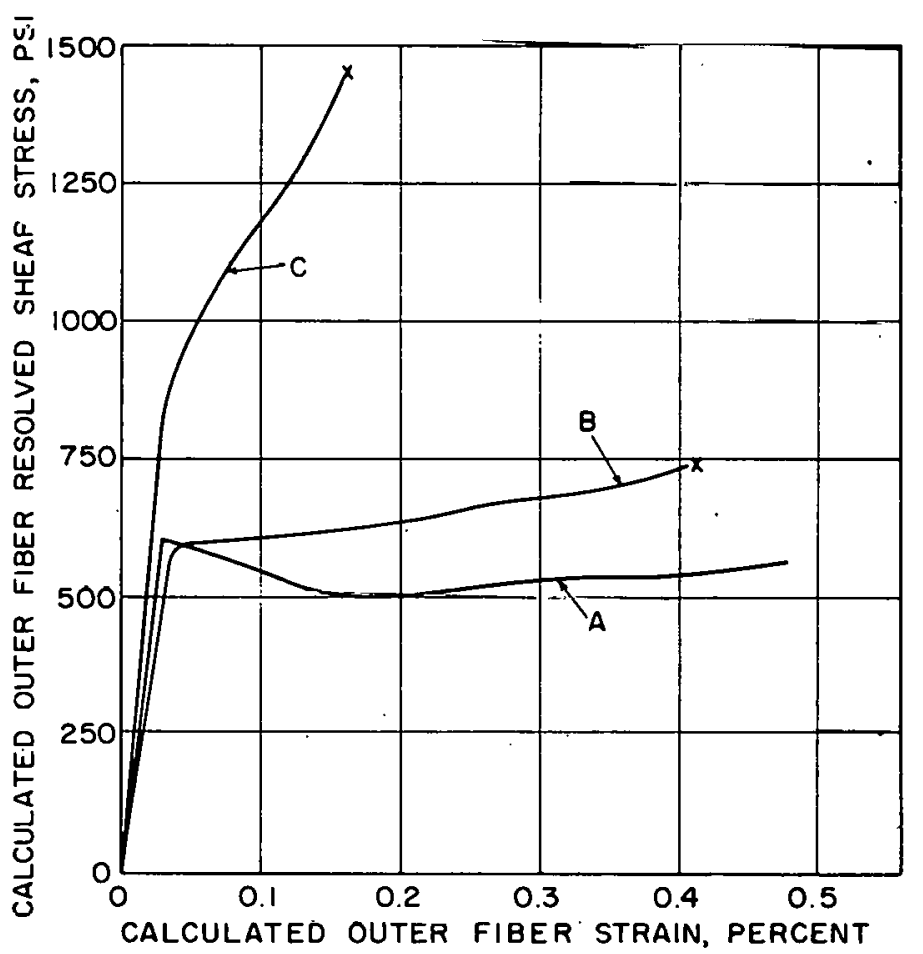

$M U-28167$

Fig. 14. Resolved-stress vs strain in bending for the same crystals shown in Fig. 13. 
orientations was 590 and 648 psi respectively.

C. Deformation of Polycrystalline LiF

Polycrystalline specimens were made from the same purified material as the single-crystal specimens. They were 2 in. long by 0.350 in. wide, and about 0.1 in。 thick. Tests were carried out in four-point bending on a 1.25-in. support span with a 0.75-in. center span of constant moment. The grain size was relatively large in all cases and ranged from 11 to 29 grains inside the 1.25-in. span. Each grain extended through the thickness of the sample.

1. Macroscopic Stress-Strain Curves

Figure 15 shows stress-strain curves for several polycrystalline specimens, and Table $I$ is a tabulation of data for the specimens. The outer fiber yield stress ranged from 1030 to 1730 psi. It was found that grain growth occurred during the annealing; therefore, to obtain small grain specimens, $D$ and $E$ were tested without a final anneal. The two ingots from which $D$ and $E$ were cutwere cooled on the same schedule as annealed specimens. $D$ and $E$ were then cut from the ingots (without cementing), chemically polished, and then tested. The other specimens were cut and annealed as described in Sec. II-C.

All polycrystalline specimens underwent some plastic deformation before fracture. Specimens $K$ and $L$ were unusual in the large amount of plastic deformation preceding fracture. In both specimens, the major part of the deformation occurred in local areas where one or more favorably oriented grains extended across the width of the specimen. Therefore, it is thought that the plastic deformation of these two samples was not representative of true polycrystalline behavior, but rather of the local deformation of individual large grains. However, as is mentioned later, the influence of grain boundaries on the fracture of these samples cannot be neglected.

\section{Observations on Etched Polycrystals}

Figure 16 is a photograph of the four sides of specimen $\mathrm{J}$ after $\mathrm{r}$ it had been tested in bending and etched in $4 \% \mathrm{HBF}_{4^{\circ}}$ The specimen was polished before annealing. Considerable grain growth 


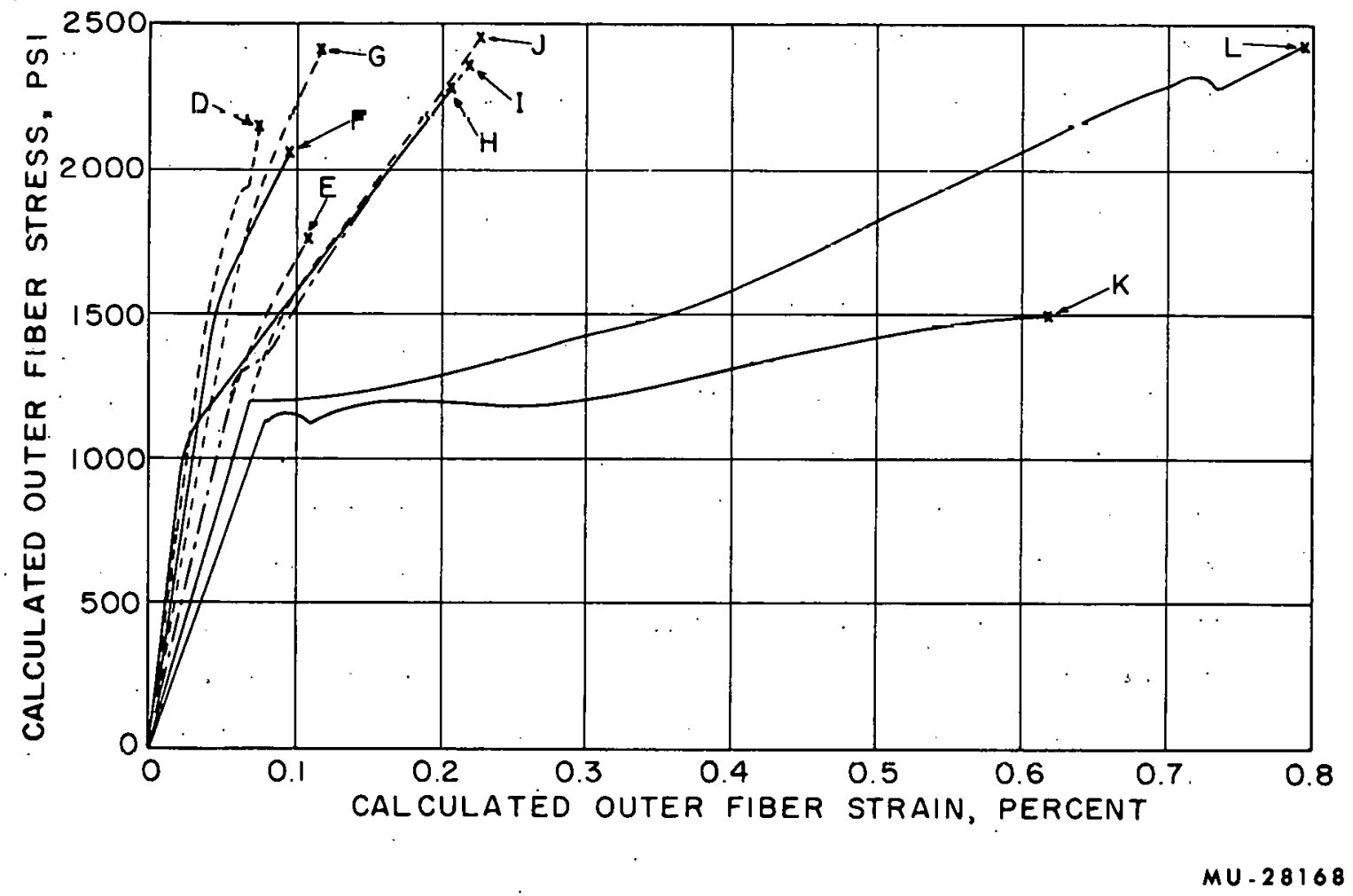

Fig. 15. Stress-strain in bending for polycrystalline LiF. 
Table I. Grain size and stress-strain values for polycrystalline lithium fluoride.

\begin{tabular}{|c|c|c|c|c|c|c|}
\hline Specimen & $\begin{array}{l}\text { Strain at } \\
\text { yield } \\
(\%)\end{array}$ & $\begin{array}{l}\text { Yield } \\
\text { stress } \\
\text { (psi) }\end{array}$ & $\begin{array}{l}\text { Strain at } \\
\text { fracture } \\
(\%)\end{array}$ & $\begin{array}{l}\text { Fracture } \\
\text { stress } \\
\text { (psi) }\end{array}$ & $\begin{array}{c}\text { Number of grains } \\
\text { (within support } \\
\text { span) }\end{array}$ & $\begin{array}{l}\text { Length of grain boundaries } \\
\text { (on tension surface within } \\
\text { support span) } \\
(\mathrm{cm}) \\
\end{array}$ \\
\hline D & 0.04 & 1530 & 0.076 & 2150 & 29 & 12.5 \\
\hline $\mathrm{E}$ & 0.06 & 1195 & 0.112 & 1730 & 28 & 11.6 \\
\hline$F$ & 0.043 & 1510 & 0.096 & 2070 & 22 & 12.0 \\
\hline G & 0.061 & 1730 & 0.118 & 2420 & 20 & 10.6 \\
\hline $\mathrm{H}$ & 0.025 & 1030 & 0.206 & 2280 & 17 & 8.1 \\
\hline I & 0.068 & 1300 & 0.22 & 2360 & 11 & 6.0 \\
\hline $\mathrm{J}$ & 0.08 & 1400 & 0.228 & 2460 & 17 & 8.2 \\
\hline $\mathrm{K}$ & 0.08 & 1125 & 0.624 & 1500 & 14 & 7.0 \\
\hline L & 0.064 & 1200 & 0.798 & 2430 & 14 & 8.0 \\
\hline
\end{tabular}




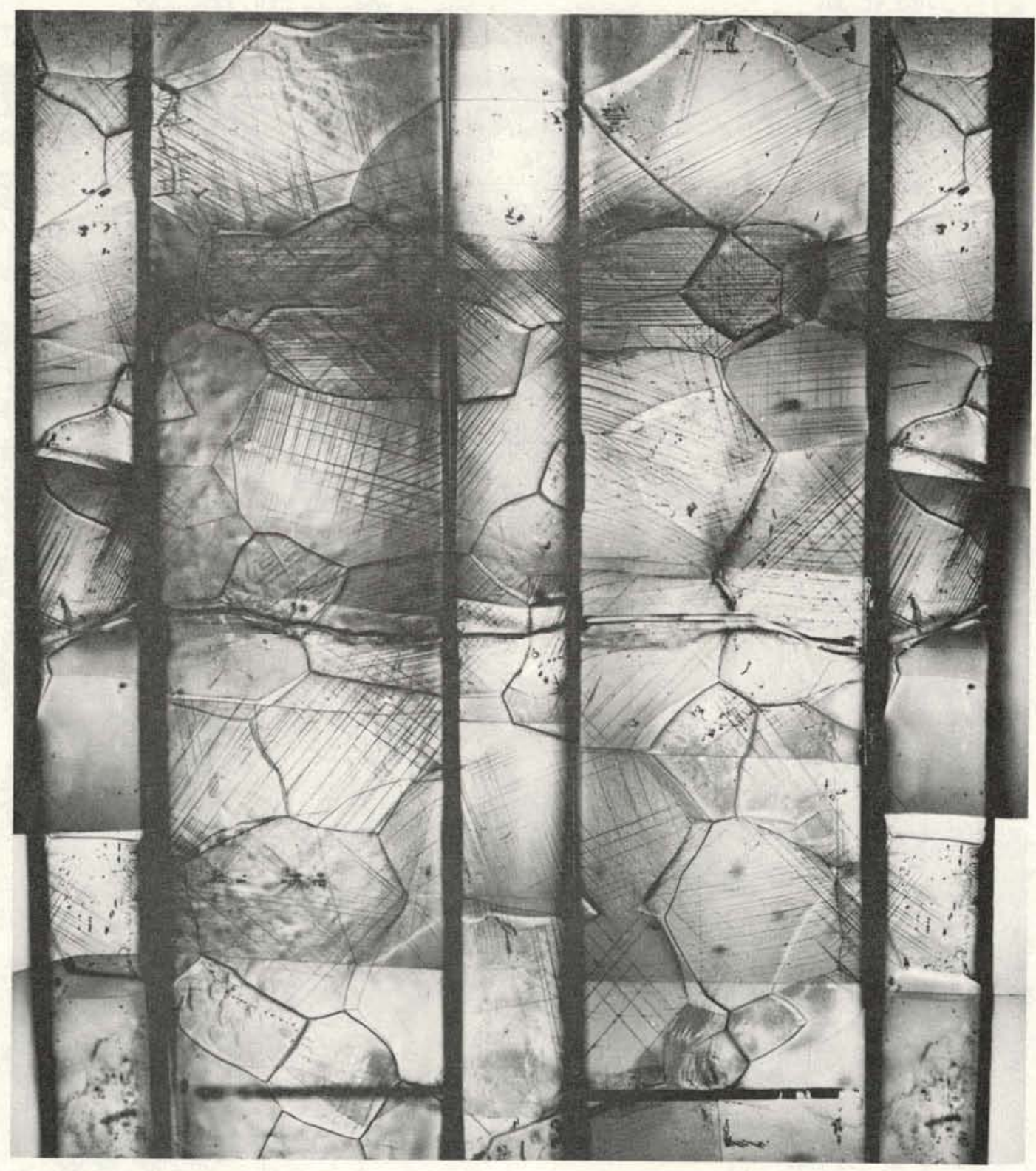

\section{COMPRESSION \\ SURFACE}

TENSION
SURFACE

Fig. 16. Polycrystalline specimen $\mathrm{J}$ etched after a bend test to fracture. Solid dark lines on the tension surface mark the support points. The load points are visible on the compression surface. The horizontal line through the center of the specimen is the fracture. Transmitted light, mosaic picture, 5. $2 \mathrm{X}$. 
occurred during the anneal, but the original grain boundaries as delineated by the polish are still visible in the figure. The general appearance of this specimen is typical of the deformed polycrystalline specimens. The deformation was inhomogeneous from grain to grain, and this behavior is attributed to the various orientations of the individual grains with respect to the applied stress. The deformation was also inhomogeneous within the grains, and local deformation at grain boundaries may be seen in several places.

A photomicrograph of the three-grain junction at the upper right of the tension surface in Fig. 16 is shown in Fig. 17a. The three grains are identified as $\mathrm{J}-1, \mathrm{~J}-2$, and $\mathrm{J}-3$ in Fig. 17a. Grain $\mathrm{J}-3$ shows the position of the three-grain junction before annealing because of the slight selectivity of the polishing solution which was applied prior to annealing. Local deformation may be seen in J-2 at the boundary between $\mathrm{J}-2$ and $\mathrm{J}-3$. Local deformation can also be seen spreading from the junction into $\mathrm{J}-1$ and $\mathrm{J}-3$. Figure $17 \mathrm{~B}$ is the same area under cross nicols. The light regions are first-order white birefringence which indicate areas of residual stresses. Figure $17 \mathrm{C}$ is a further magnification of a portion of the horizontal boundary between $\mathrm{J}-2$ and $\mathrm{J}-3$ showing the fine, local boundary slip.

Figure 18 shows the orientation of the three grains of Fig. 17, and a more complete stereographic projection for grain J-2 is given in Fig. 19. This figure, like Fig. 18, is plotted with the pole of the tension surface at the center of the projection. The sliptraces on the tension surface of the crystal appear on the stereographic projection as points on the basic circle. By measuring the angular positions of the slip traces in the crystal, and comparing them with the positions of the plane traces in the stereographic projection, the slip planes corresponding to the traces in the crystal can be identified. The angles were measured either on a microscope stage or with a protractor on a tracing from a photomicrograph, and the projections were plotted using a $20-\mathrm{cm}$ Wulff Net. Fifty-four slip traces were measured on 14 grains of various orientations, and compared with the corresponding plane traces in the 


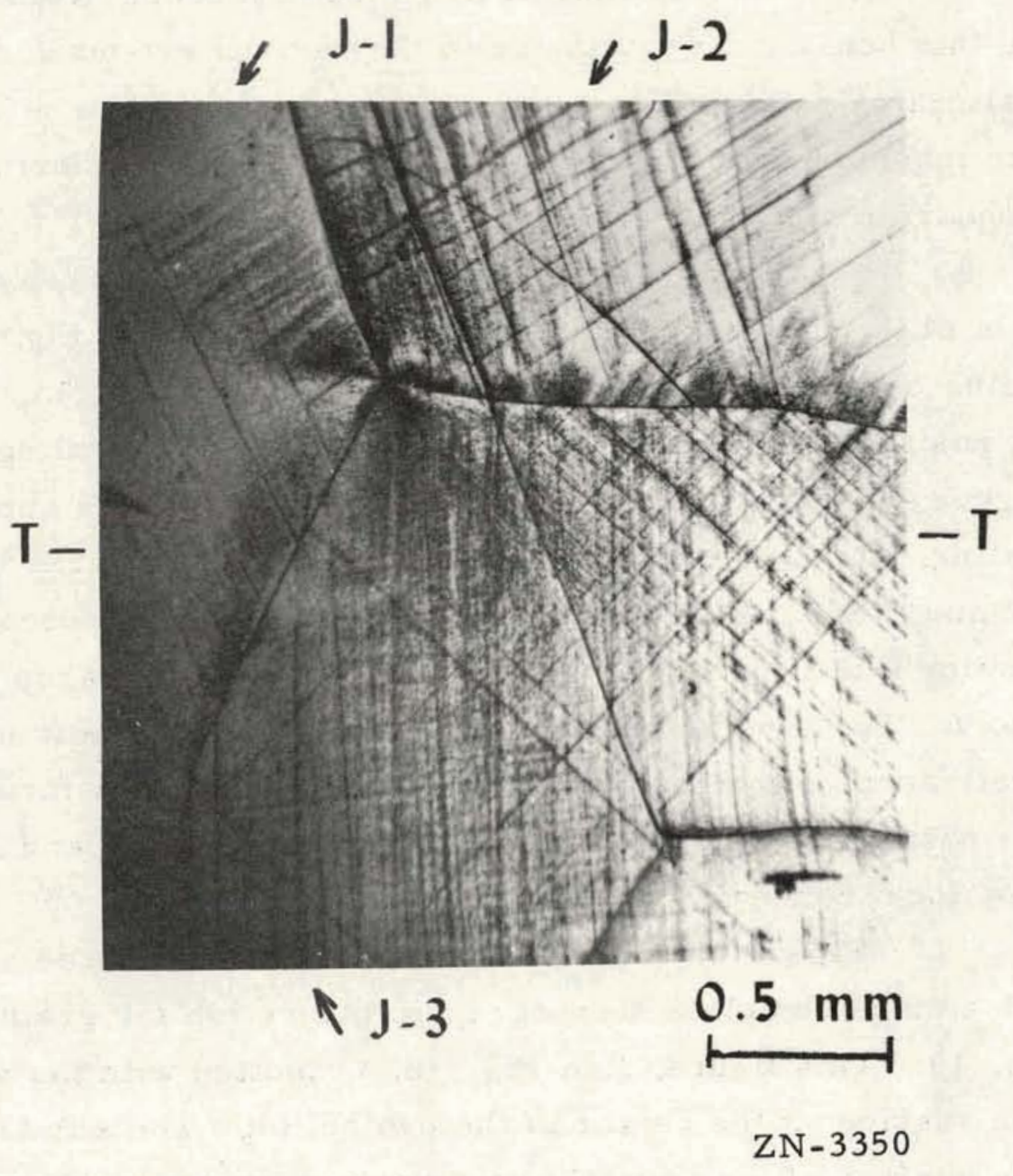

Fig. 17A. Three-grain junction, tension surface, specimen J. The tension direction is labelled $\mathrm{T}$. 


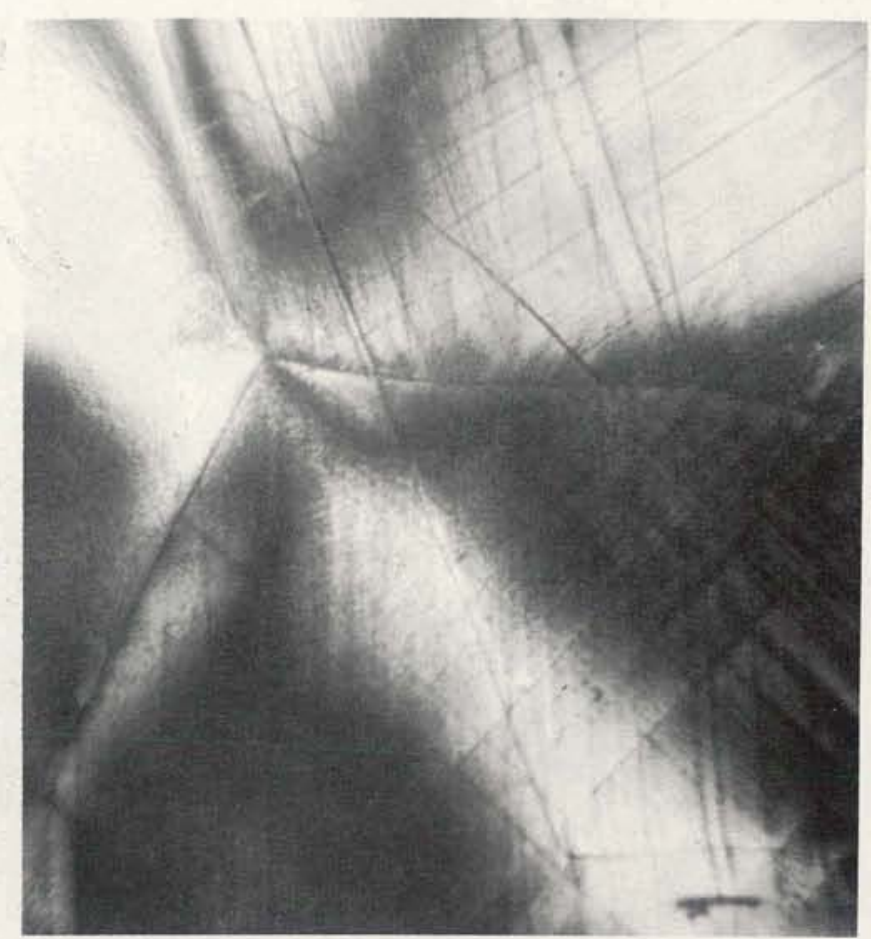

$\mathrm{ZN}-3346$

Fig. 17B. Same area as shown in Fig. 17A, but with crossed nicols. 


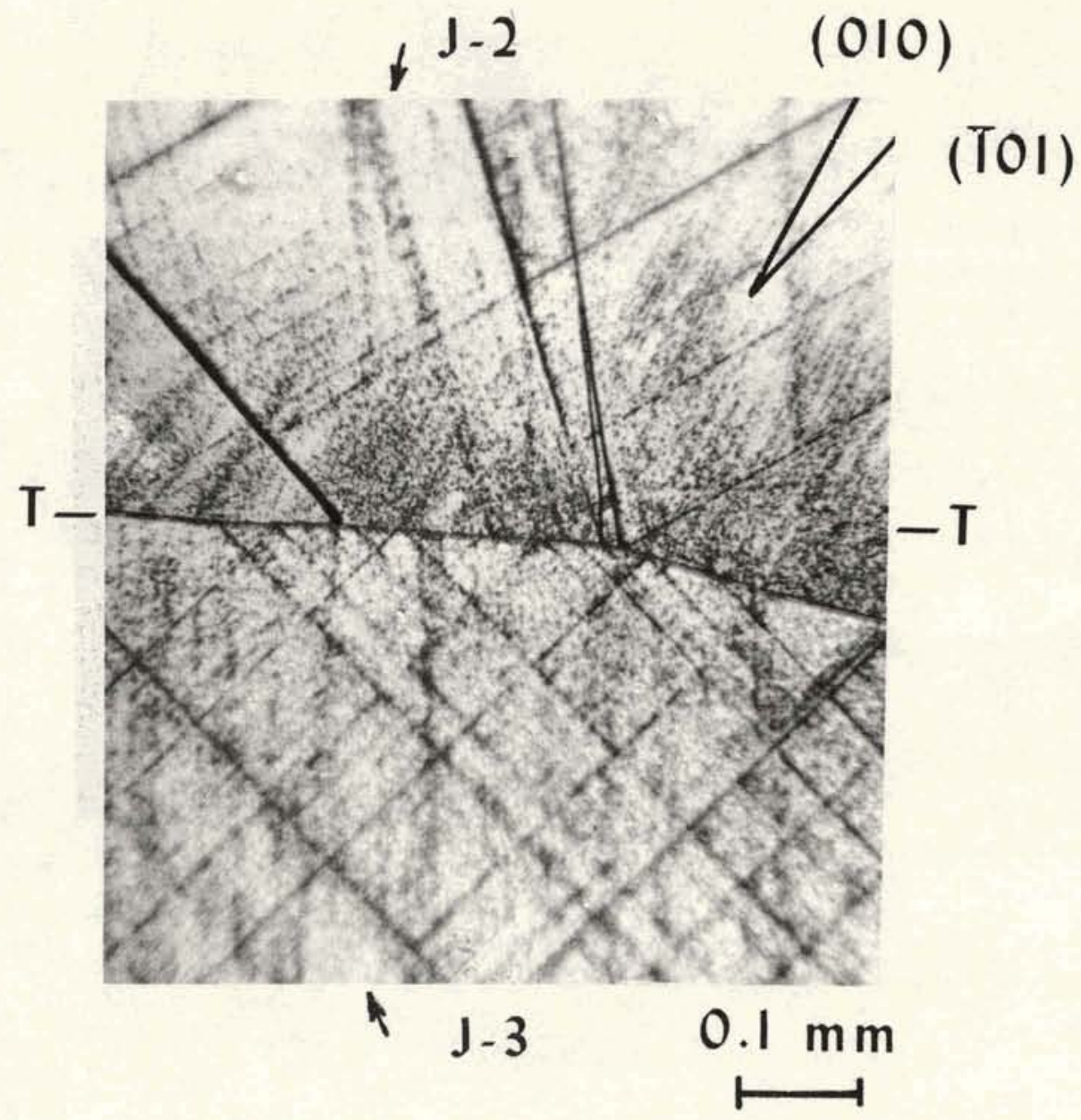

ZN-3351

Fig. 17C. A section of the horizontal boundary between grains $\mathrm{J}-2$ and $\mathrm{J}-3$. 


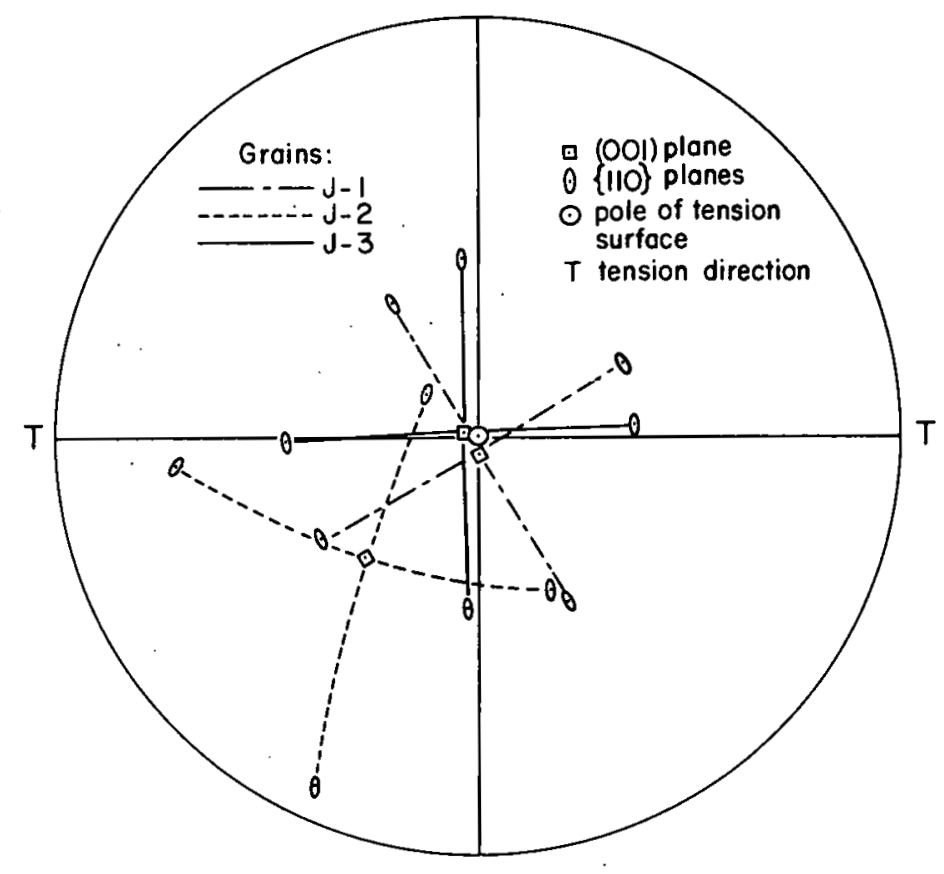

MU.28199

Fig. 18. Stereographic projection for the three grains shown in Figs. $17 \mathrm{~A}-\mathrm{C}$. 


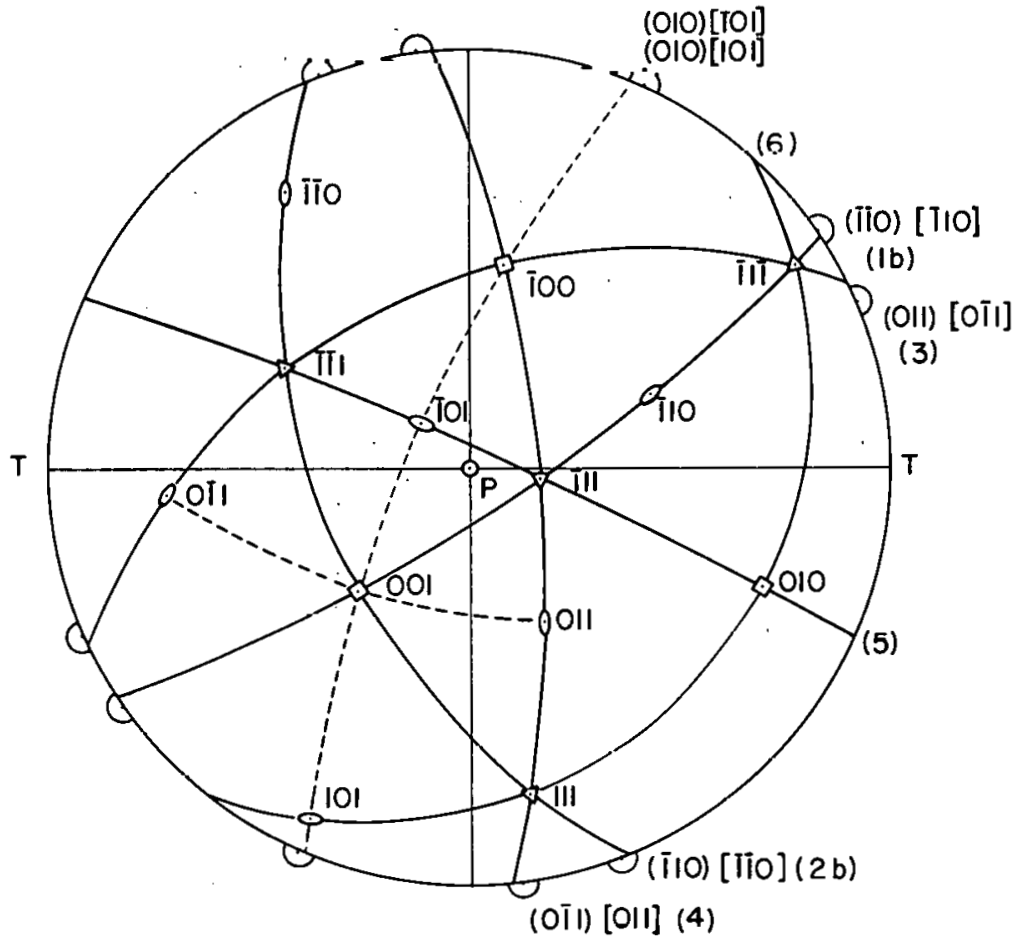

MU.28200

Fig. 19. Complete stereographic projection for grain J-2. 
appropriate stereographic projections. Fifty measured slip traces were within \pm 2 deg of the plotted plane traces. Two slip traces were $3 \mathrm{deg}$ in error, and two others were $4 \mathrm{deg}$ in error. A summary of the orientation data for the slip systems: in grains $\mathrm{J}-1, \mathrm{~J}-2$, and $\mathrm{J}-3$ is given in Table II. For. reference, a standard (001) stereographic projection and a numbering system for slip systems of the type $\{110\}$ (110) are given in Fig. 20 and Table III.

The fine boundary slip in J-2, shown.in Fig. 17C, corresponds on the stereographic projection for this crystal to the (010) slip plane. The nearest $\{110\}$ type plane that might correspond to the observed trace is the (i0l) plane. However, this plane is 15 deg away from the measured position of the slip trace and is outside the range of error in these measurements. A comparison of the positions of the $(010)$ and (i01) traces is given in Fig. 17C.

There are two possible slip directions in the (010) plane: [101] and [101]. It cannot be determined from Fig. 19 alone which slip direction was operating. The (010) plane made an angle of 73 deg with the surface of the specimen, and the [j01] and [101] slip directions made angles with the slip trace of 85 and 5 deg respectively. Therefore, at the surface, the dislocations were either almost pure screw-or almost pure edge-type.

Crystal J-3 on the other side of this boundary was very close to the usual $\{100\}$ cleaved single-crystal orientation. The diagonal slip traces in this crystal were edge bands; the vertical traces were screw. If the displacement caused at the boundary by these edge bands was relieved by local plastic flow in $\mathrm{J}-2$, then the fine boundary slip in $\mathrm{J}-2$ was probably on the system (010)[101], i.e., nearly edge-type. The resolved-shear stress on this slip system from the applied load was, at the fracture stress for this specimen, about 880 psi; for the other slip system, (010) [ $\overline{1} 01]$, it was about 540 psi. 
Table $n$. Orientation data for slip systems in individual grains. ${ }^{a}$

\begin{tabular}{|c|c|c|c|c|c|c|c|c|c|}
\hline Grain & & $\begin{array}{c}\text { Slip } \\
\text { system }\end{array}$ & $\lambda$ & $\theta$ & $\cos \lambda \cos \theta$ & $\begin{array}{l}\text { Plane } \\
\text { angle } \\
\end{array}$ & $\begin{array}{c}\text { Direction } \\
\text { angle }\end{array}$ & Remarks & \\
\hline$J-1$ & & $\begin{array}{l}6 \\
5 \\
4 \\
3 \\
3 \mathrm{~b} \\
1 \mathrm{~b}\end{array}$ & $\begin{array}{l}69 \\
68 \\
53 \\
53 \\
76 \\
13\end{array}$ & $\begin{array}{l}68 \\
69 \\
53 \\
91 \\
13 \\
76\end{array}$ & $\begin{array}{l}0.13 \\
0.13 \\
0.36 \\
0.34 \\
0.24 \\
0.24\end{array}$ & \begin{tabular}{l}
42 \\
48 \\
47 \\
$A 3$ \\
\hdashline- \\
\hdashline-
\end{tabular} & $\begin{array}{l}87 \\
86 \\
86 \\
85 \\
-- \\
--\end{array}$ & $\begin{array}{l}\text { Small local slip } \\
\text { Small local slip } \\
\text { Long slip throughout crystal } \\
\text { Long slip throughout crystal } \\
\text { Nut upe iutiug } \\
\text { Not operating }\end{array}$ & . \\
\hline$J-2$ & & 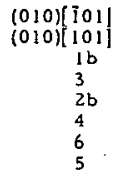 & $\begin{array}{l}27 \\
27 \\
57 \\
72 \\
45 \\
19 \\
76 \\
66\end{array}$ & $\begin{array}{l}76 \\
66 \\
45 \\
19 \\
57 \\
72 \\
66 \\
76\end{array}$ & $\begin{array}{l}0.22 \\
0.36 \\
0.38 \\
0.79 \\
0.38 \\
0.29 \\
0.10 \\
0.10\end{array}$ & $\begin{array}{l}73 \\
73 \\
77 \\
44 \\
50 \\
72 \\
--\end{array}$ & $\begin{array}{r}85 \\
5 \\
42 \\
25 \\
18 \\
50 \\
-- \\
--\end{array}$ & $\begin{array}{l}\text { Boundary slip, two possible } \\
\text { systetus } \\
\text { Heavy, long slip } \\
\text { Light slip } \\
\text { Heavy, long slip } \\
\text { Light slip } \\
\text { Not operating } \\
\text { Not operating }\end{array}$ & \\
\hline $\mathrm{J}-3$ & . & $\begin{array}{l}3 \\
4 \\
1 \mathrm{c} \\
2 \mathrm{c} \\
5 \\
6\end{array}$ & $\begin{array}{l}48 \\
42 \\
43 \\
47 \\
89 \\
86\end{array}$ & $\begin{array}{l}42 \\
48 \\
47 \\
43 \\
86 \\
89\end{array}$ & $\begin{array}{l}0.50 \\
0.50 \\
0.50 \\
0.50 \\
0.00 \\
0.00\end{array}$ & $\begin{array}{l}42 \\
49 \\
86 \\
88 \\
-- \\
--\end{array}$ & $\begin{array}{r}88 \\
88 \\
2 \\
4 \\
-- \\
--\end{array}$ & $\begin{array}{l}\text { Moderate slip } \\
\text { Heavy slip } \\
\text { Heavy slip } \\
\text { Heavy slip } \\
\text { Not operating } \\
\text { Not operating }\end{array}$ & \\
\hline$J-4$ & & $\begin{array}{l}1 \mathrm{c} \\
2 \mathrm{c} \\
3 \\
6 \\
5 \\
4\end{array}$ & $\begin{array}{l}31 \\
71 \\
72 \\
56 \\
89 \\
29\end{array}$ & $\begin{array}{l}71 \\
31 \\
29 \\
89 \\
56 \\
72\end{array}$ & $\begin{array}{l}0.28 \\
0.28 \\
0.27 \\
0.00 \\
0.00 \\
0.27\end{array}$ & $\begin{array}{l}68 \\
82 \\
25 \\
-- \\
\because- \\
--\end{array}$ & $\begin{array}{r}9 \\
22 \\
69 \\
\because- \\
\because-\end{array}$ & $\begin{array}{l}\text { Light slip } \\
\text { Heavy boundary slip } \\
\text { Moderate slip throughout crystal } \\
\text { Not Operating } \\
\text { Not Operating } \\
\text { Not operating }\end{array}$ & \\
\hline$J-5$ & & $\begin{array}{l}3 \\
1 b \\
2 b \\
4 \\
6 \\
5\end{array}$ & $\begin{array}{l}50 \\
42 \\
48 \\
10 \\
85 \\
89\end{array}$ & $\begin{array}{l}40 \\
48 \\
42 \\
50 \\
89 \\
85\end{array}$ & $\begin{array}{l}0.49 \\
0.50 \\
0.50 \\
0.49 \\
0.00 \\
0.00\end{array}$ & $\begin{array}{l}41 \\
86 \\
79 \\
51 \\
-- \\
--\end{array}$ & $\begin{array}{r}74 \\
11 \\
4 \\
76 \\
\because- \\
--\end{array}$ & $\begin{array}{l}\text { Moderate slip throughout crystal } \\
\text { Moderate slip throughout crystal } \\
\text { Moderate slip throughout crystal } \\
\text { Mluderato clip throughout crystal } \\
\text { Not nperating } \\
\text { Not operating }\end{array}$ & \\
\hline $11-1$ & & $\begin{array}{l}2 \\
3 \\
5 \\
4 \\
6 \\
1\end{array}$ & $\begin{array}{l}83 \\
51 \\
60 \\
60 \\
68 \\
10\end{array}$ & $\begin{array}{l}10 \\
60 \\
68 \\
51 \\
60 \\
83\end{array}$ & $\begin{array}{l}0.12 \\
0.31 \\
0.19 \\
0.31 \\
0.19 \\
0.12\end{array}$ & $\begin{array}{l}51 \\
76 \\
30 \\
31 \\
76 \\
--\end{array}$ & $\begin{array}{l}0 \\
62 \\
26 \\
28 \\
62 \\
--\end{array}$ & $\begin{array}{l}\text { Very light, upper part } \\
\text { Very light, lower part } \\
\text { Major sllp, upper half crystal } \\
\text { Major slip into boundary } \\
\text { Fine slip, upper boundary } \\
\text { Not operating }\end{array}$ & . \\
\hline $\mathrm{H}-2$ & & $\begin{array}{l}4 \\
6 \\
3 \\
5 \\
1 \mathrm{a} \\
2 \mathrm{a}\end{array}$ & $\begin{array}{l}68 \\
14 \\
46 \\
84 \\
73 \\
55\end{array}$ & $\begin{array}{l}46 \\
84 \\
68 \\
14 \\
55 \\
73\end{array}$ & $\begin{array}{l}0.26 \\
0.10 \\
0.26 \\
0.10 \\
0.17 \\
0.17\end{array}$ & $\begin{array}{l}35 \\
90 \\
87 \\
30 \\
-- \\
--\end{array}$ & $\begin{array}{r}4 \\
60 \\
54 \\
2 \\
-- \\
--\end{array}$ & $\begin{array}{l}\text { Major slip throughout crystal } \\
\text { Very light } \\
\text { Very light } \\
\text { Major slip throughout crystal } \\
\text { Not operating } \\
\text { Not operating }\end{array}$ & \\
\hline $\mathrm{H}-3$ & & $\begin{array}{l}1 \\
5 \\
6 \\
2 \\
3 \\
4\end{array}$ & $\begin{array}{l}59 \\
50 \\
42 \\
31 \\
76 \\
84\end{array}$ & $\begin{array}{l}31 \\
42 \\
50 \\
59 \\
84 \\
76\end{array}$ & $\begin{array}{l}0.44 \\
0.48 \\
0.48 \\
0.44 \\
0.02 \\
0.02\end{array}$ & $\begin{array}{l}86 \\
48 \\
48 \\
77 \\
-- \\
--\end{array}$ & $\begin{array}{r}13 \\
64 \\
64 \\
4 \\
-- \\
--\end{array}$ & $\begin{array}{l}\text { Major slip, upper part crystal } \\
\text { Light } \\
\text { Very light, three lines only } \\
\text { Major slip, lower part crystal } \\
\text { Not operating } \\
\text { Not operating }\end{array}$ & \\
\hline $\mathrm{H}-4$ & . & $\begin{array}{l}1 \mathbf{a} \\
6 \\
3 \\
5 \\
4 \\
2 \mathbf{a}\end{array}$ & $\begin{array}{l}77 \\
40 \\
58 \\
66 \\
80 \\
20\end{array}$ & $\begin{array}{l}20 \\
66 \\
80 \\
40 \\
58 \\
77\end{array}$ & $\begin{array}{l}0.21 \\
0.31 \\
0.09 \\
0.31 \\
0.09 \\
0.21\end{array}$ & $\begin{array}{l}43 \\
83 \\
32 \\
31 \\
83 \\
--\end{array}$ & $\begin{array}{r}0 \\
59 \\
14 \\
13 \\
58 \\
--\end{array}$ & $\begin{array}{l}\text { Light } \\
\text { Light } \\
\text { Light horizontal top and bottom } \\
\text { Major slip into boundary } \\
\text { Light vertical at Rt. boundary } \\
\text { Not operating }\end{array}$ & \\
\hline$H-5$ & . & $\begin{array}{l}1 \\
5 \\
6 \\
2 \\
3 \\
4\end{array}$ & $\begin{array}{l}10 \\
51 \\
57 \\
80 \\
64 \\
69\end{array}$ & $\begin{array}{l}80 \\
57 \\
51 \\
10 \\
69 \\
64\end{array}$ & $\begin{array}{l}0.17 \\
0.34 \\
0.34 \\
0.17 \\
0.16 \\
0.16\end{array}$ & $\begin{array}{l}87 \\
47 \\
43 \\
90 \\
-- \\
--\end{array}$ & $\begin{array}{r}0 \\
88 \\
86 \\
3 \\
-- \\
--\end{array}$ & $\begin{array}{l}\text { Moderate, near horizontal } \\
\text { Long slip, Fig. } 22 a \\
\text { Long slip, Fig. 22a } \\
\text { Moderate, near vertical } \\
\text { Very light, one or two lines } \\
\text { Not operating }\end{array}$ & \\
\hline
\end{tabular}

${ }^{a}$ The numbering system for $\{110\}$ (110)type slip systems is given in Tablelll. The is the anule between the iormal to the slip plane and the tension or compression axis (taken as the specimen axis), and $\theta$ is the angle between the slip direction and this axis. The heading "Plane angle" refers to the angle that the slip plane makes with the tension or compression surface. The heading "Direction angle" refers to the angle that the slip direction makes whth the slip trace on the tension or compression surface. All operating slip systems in a grain are
listed in the sequence in which their slip trace appears in the appropriate figure, starting at the vertical and going clockwise.

This system, the alte rnate possibility to the $(010)$ system, was operating in another part of this grain. The measured angles between the traces of the $(010)$ and (i01) agreed with the plotted angles of Fig. 19. 


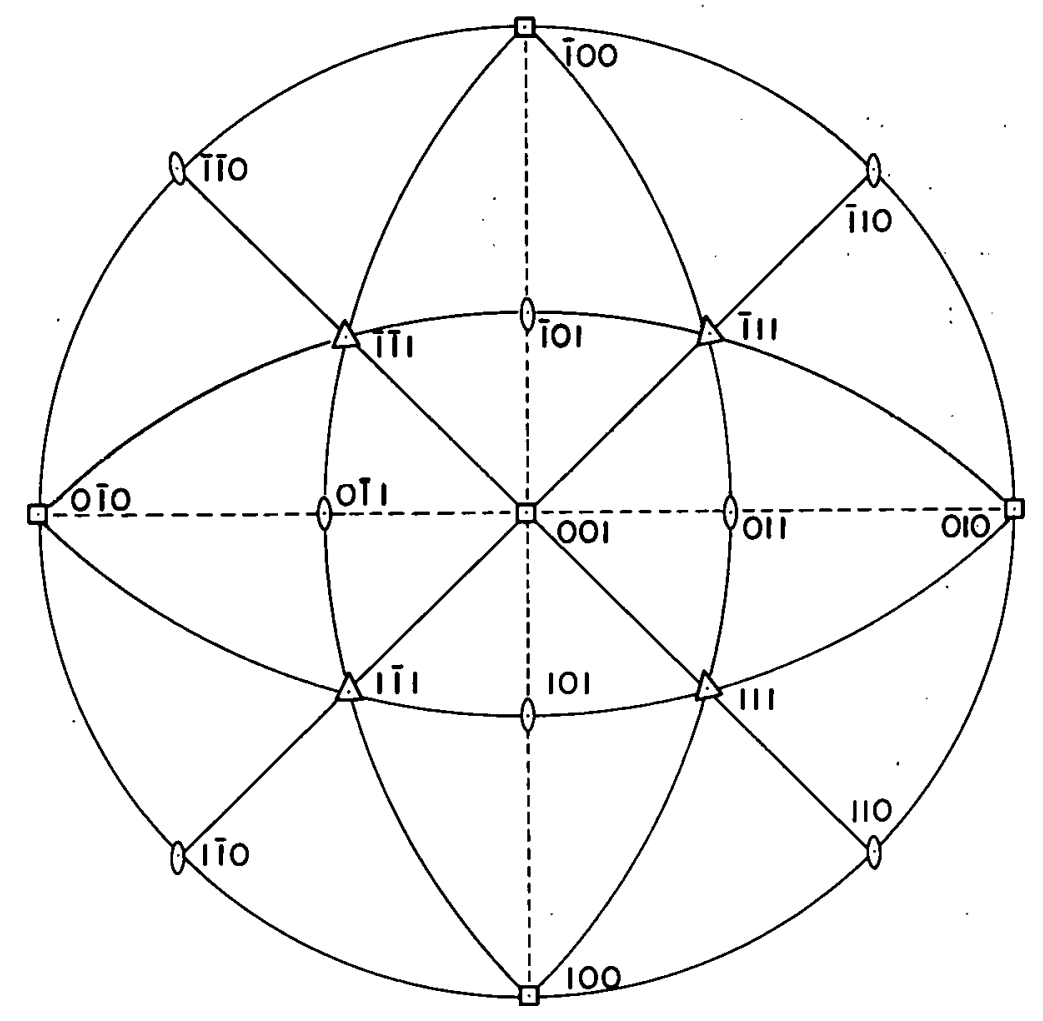

MU. 28303

Fig. 20. Standard (001) stereographic projection. 
Table III. Reference table for slip systems in an $\mathrm{NaCl}$ structure, as seen in a standard (001) stereographic projection.

\begin{tabular}{|c|c|c|c|c|c|c|c|}
\hline No. & $\begin{array}{l}\text { Slip } \\
\text { system }\end{array}$ & No. & $\begin{array}{l}\text { Slip } \\
\text { system }\end{array}$ & No. & $\underset{\text { system }}{\text { Slip }}$ & No. & $\begin{array}{l}\text { Slip } \\
\text { system }\end{array}$ \\
\hline 1 & $(110)\left[\begin{array}{ll}1 & 10\end{array}\right]$ & la & $(110)[1 \overline{1} 0]$ & $\mathrm{Ib}$ & $(\overline{1} \overline{1} 0)[\overline{1} 10]$ & lc & $(110)[\bar{I} 10]$ \\
\hline 2 & ( $1 \overline{1} 0)[\overline{1} \overline{1} 0]$ & $2 a$ & $(1 \overline{1} 0)[110]$ & $2 \mathrm{~b}$ & $(\overline{1} 10)\left[\begin{array}{l}\overline{1} \\
10\end{array}\right]$ & $2 c$ & $(\overline{1} 10)\left[\begin{array}{ll}1 & 10\end{array}\right]$ \\
\hline 31 & $(011)\left[\begin{array}{lll}0 & \overline{1} & 1\end{array}\right]$ & & & & . & & \\
\hline 4 & $\left(\begin{array}{ll}0 & \overline{1} \\
1\end{array}\right)\left[\begin{array}{lll}0 & 1 & 1\end{array}\right]$ & & & & & & \\
\hline 5 & $(101)[\overline{1} 01]$ & & & & & & \\
\hline 6 & $(\overline{1} 01)[101]$ & & & & & & \\
\hline
\end{tabular}


Room-temperature slip on a $\{100\}$ plane is difficult in LiF. Gilman found that for single crystals of LiF tested in torsion, $\{100\}$ $\langle 110\rangle$ type slip did not occur below about $400^{\circ} \mathrm{K}$. Johnston, on the other hand, found this type of slip at room temperature for crystals tested in compression; ${ }^{32}$ the stress level, however, was about 15 times that necessary for $\{110\}, 110)$ type slip. It is thought that the $(010)$ boundary slip observed in this case resulted from the combination of two factors: one, a relatively high resolved stress from the applied load, and two, a high concentrated stress at the boundary resulting from large-scale deformation of the adjacent grain, J-3. It is interesting to note that considerable deformation was accommodated between grains $\mathrm{J}-2$ and $\mathrm{J}-3$ without initiating fracture.

Another interesting feature of this junction was the local slip extending upwards into $\mathrm{J}-1$ from the three-grain junction as seen in Fig. 17A. This slip pattern is similar in appearance to the shear zone predicted by Betteridge and Franklin for grain boundary sliding in creep, 26 and represented schematically by Cottrell as shown in Fig. 2. That this slip was related to some local stress may be inferred from the very low resolved stress factor $(0.13)$ of the operating systems. ( $\mathrm{J}-1,5,6$, Table II). The slip, like the (010) boundary slip mentioned previously, was confined to a local region of the crystal. Long-range slip on the other operating system ( $\mathrm{J}-1,3,4$, Table II) which had a high resolved-stress factor (0.36) may also be seen in Fig. 17A.

Figure 21A shows an example of long-range slip from a particular boundary in the compression surface of specimen $J$ (lower right, Fig. 16). The slip was associated with the diagonal boundary between grains $J-4$ and $J-5$, and it was not present along the vertical boundary indicated by the arrow in Fig. 21A. Figure $21 \mathrm{~B}$ shows the relative orientation of grains $\mathrm{J}-4$ and $J-5$, and Table II gives data for the orientation of the slipsystems. All the systems with high resolved-stress factors were operating in J-5. The systems operating in J-4 had much lower resolved-stress factors which were all approximately equal. The much denser slip in the system associated with the boundary was then 


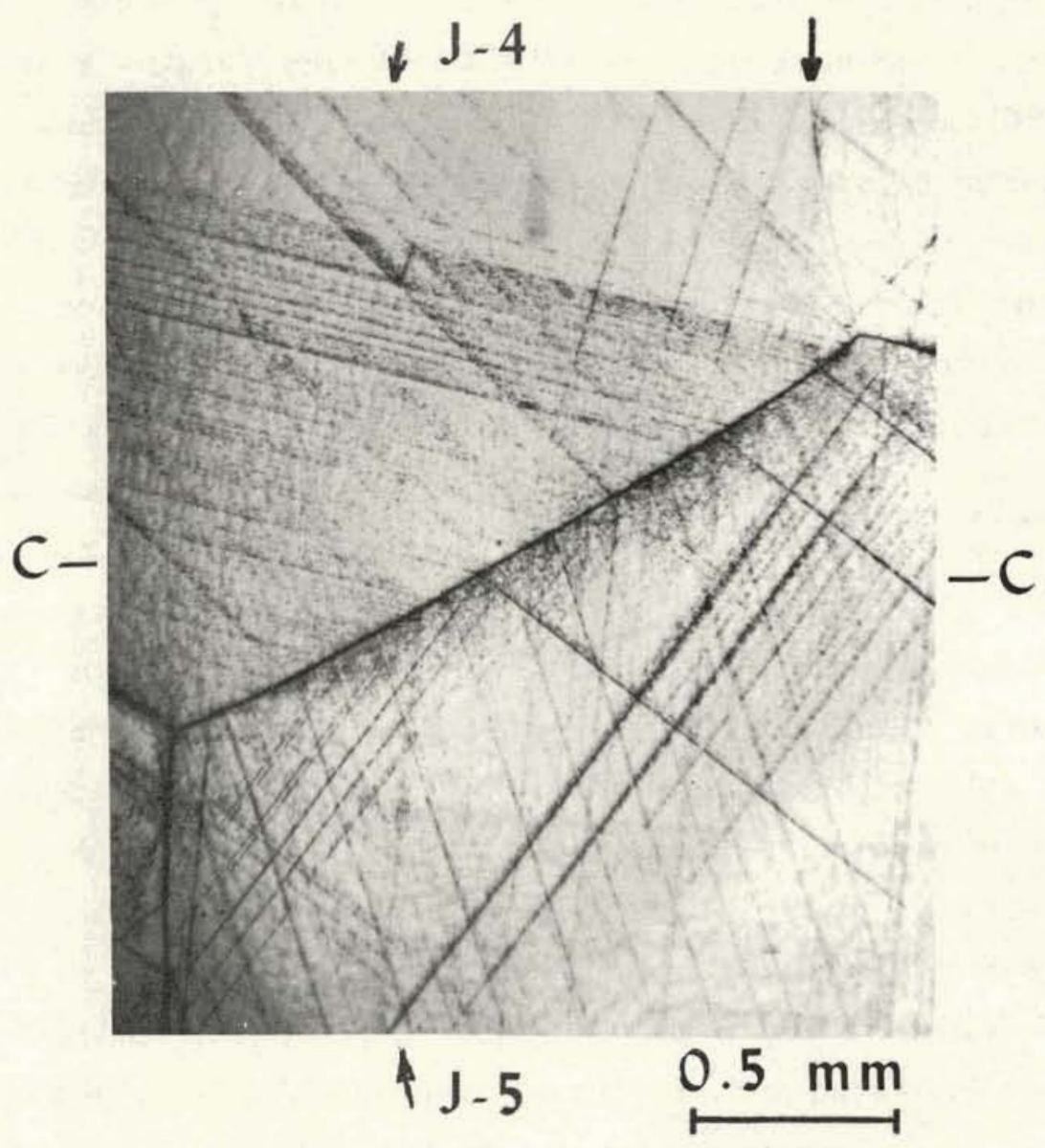

$\mathrm{ZN}-3352$

Fig. 21A. Slip from a boundary in the compression surface of specimen $J$. The compression direction is

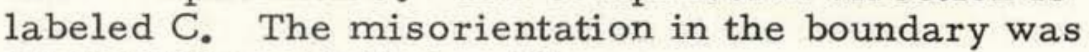
15 deg twist and 30 deg tilt. 


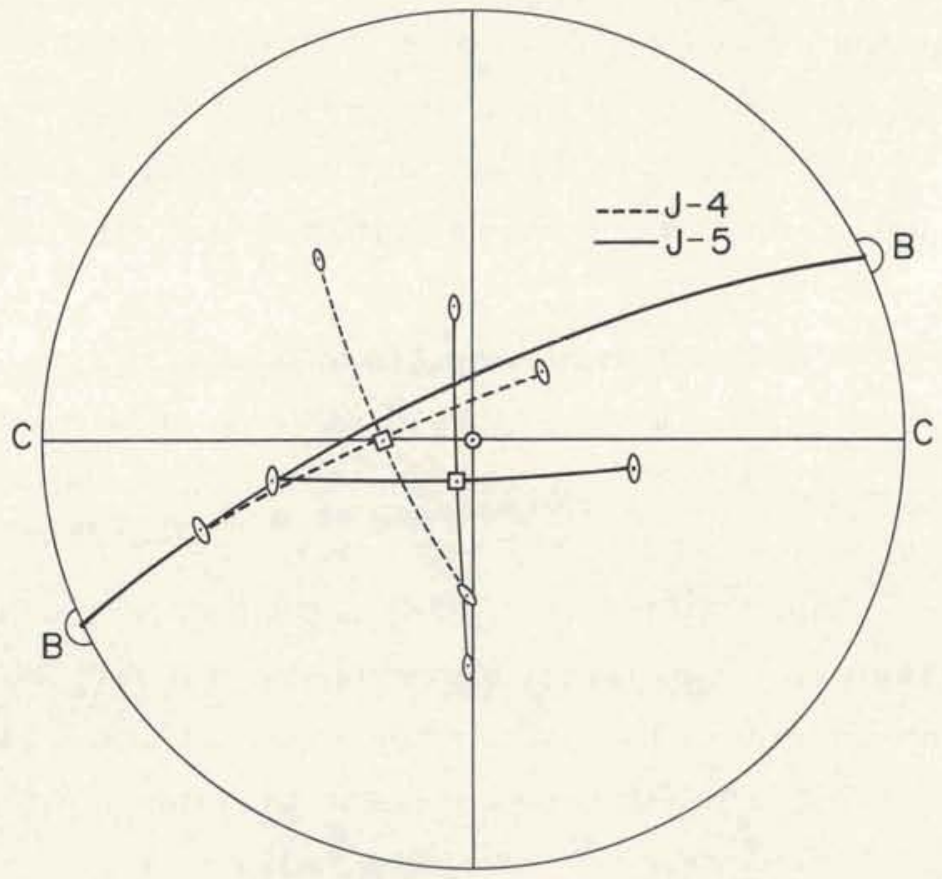

MU. 28304

Fig. 21B. Stereographic projection, grains $\mathrm{J}-4$ and $\mathrm{J}-5$, showing relative orientation. 
probably the result of stresses developed at the boundary by the deformation of the lower grain, J-5. The additional fine boundary slip (in the $\mathrm{J}-5,1 \mathrm{~b}$ slip system) was probably also due to these same stresses.

Figure 22A shows two heavily deformed grains in the tension surface of specimen L, and Fig。 22B is the stereographic projection for these grains. Both grains were close to $\{100\}$ type cleaved orientation and the misorientation between them was not large. The slip liaces running vertically in the grains were screw bands. Gilman found that screw bands were readily accommodated in a boundary in a zinc bycrys tal, ${ }^{17}$ and Fig. 22A indicates that this fact also holds for a small-angle boundary in LiF。

A more complete picture of the interaction of several grains in an aggregate is given in the data from specimen $\mathrm{H}$ in Figs. 23A-C, $24 \mathrm{~A}-\mathrm{B}$, and Table II. It was not possible to reconstruct the actual sequence of slip, but several interesting features were present.

The major slip bands, i.e., the most numerous and heavy long-range bands present in grains $\mathrm{H}-1$ through $\mathrm{H}-5$, all had considerable edge component. The slip directions of these systems made angles of from 0 to 28 deg with the slip trace in the tension surface. With the exception of two major slip systems, all the major slip systems had, at the fracture stress for this specimen (2280 psi), resolved shear stress ranging from 593 to $1094 \mathrm{psi}$. The lower value is near the value of 590 to 650 psi obtained for the resolved-yield stress for two different orientations of single crystals of this same material. The slip system No. 5 in $\mathrm{H}-2$, which slants steeply down to the right (Eig。23A and H-2, 5, Table II), was a major system of almost pure edge-type operating under a resolved-shear stress from the applied load of only $228 \mathrm{psi}$. The other major system $(\mathrm{H}-1,5)$ was operating at a resolved stress of 430 psi.

The slip systems operating in $\mathrm{H}-3$ at the boundary between $\mathrm{H}-3$ and $\mathrm{H}-4$ in Fig. 24A were probably accommodating the increased length of this boundary as H-4 deformed. Similarly, the nearly vertical and horizontal slip in $\mathrm{H}-5$ which originates at the boundary between 


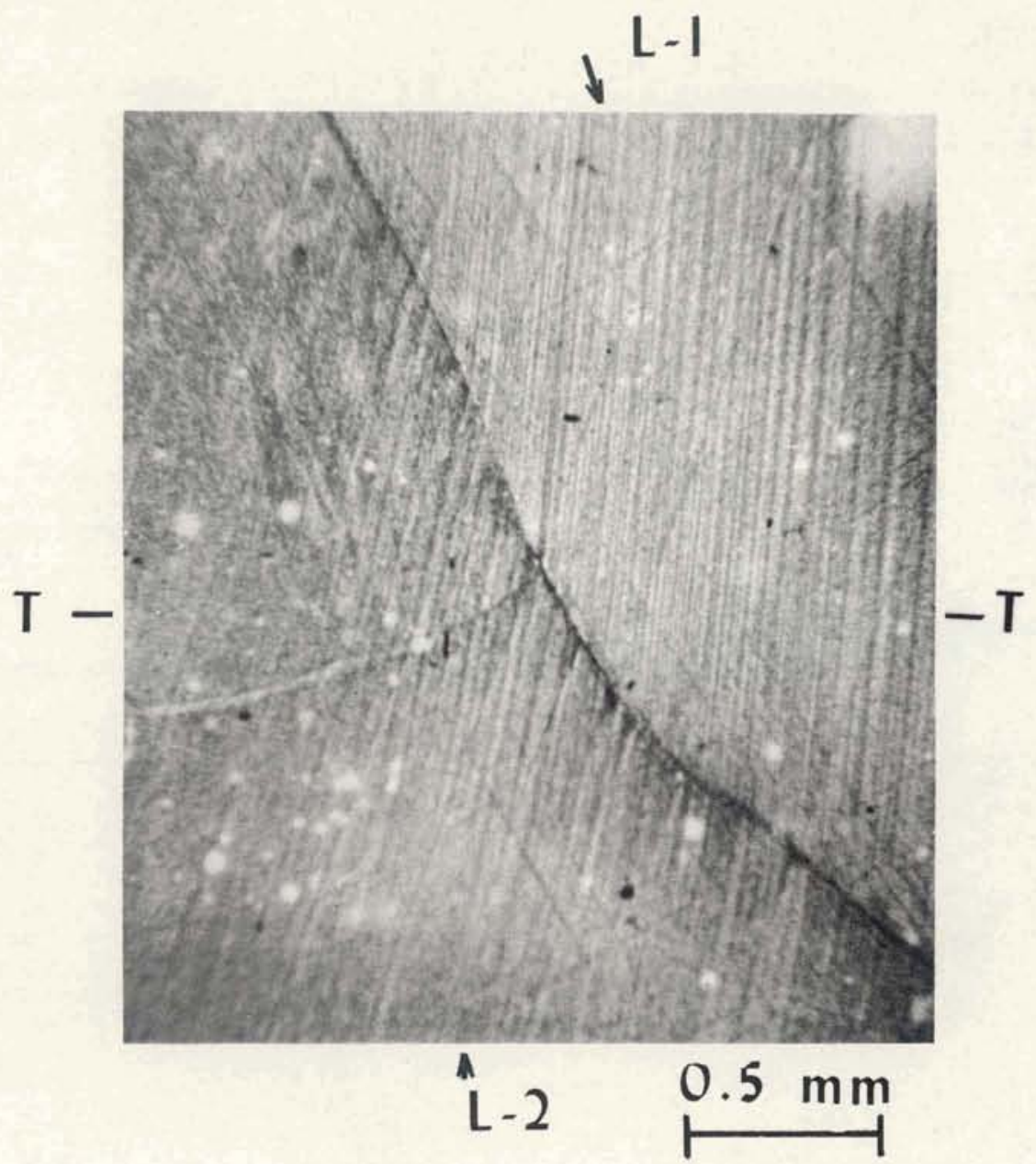

ZN-3353

Fig. 22A. Deformation at small-angle boundary in the tension surface of specimen $L$. 


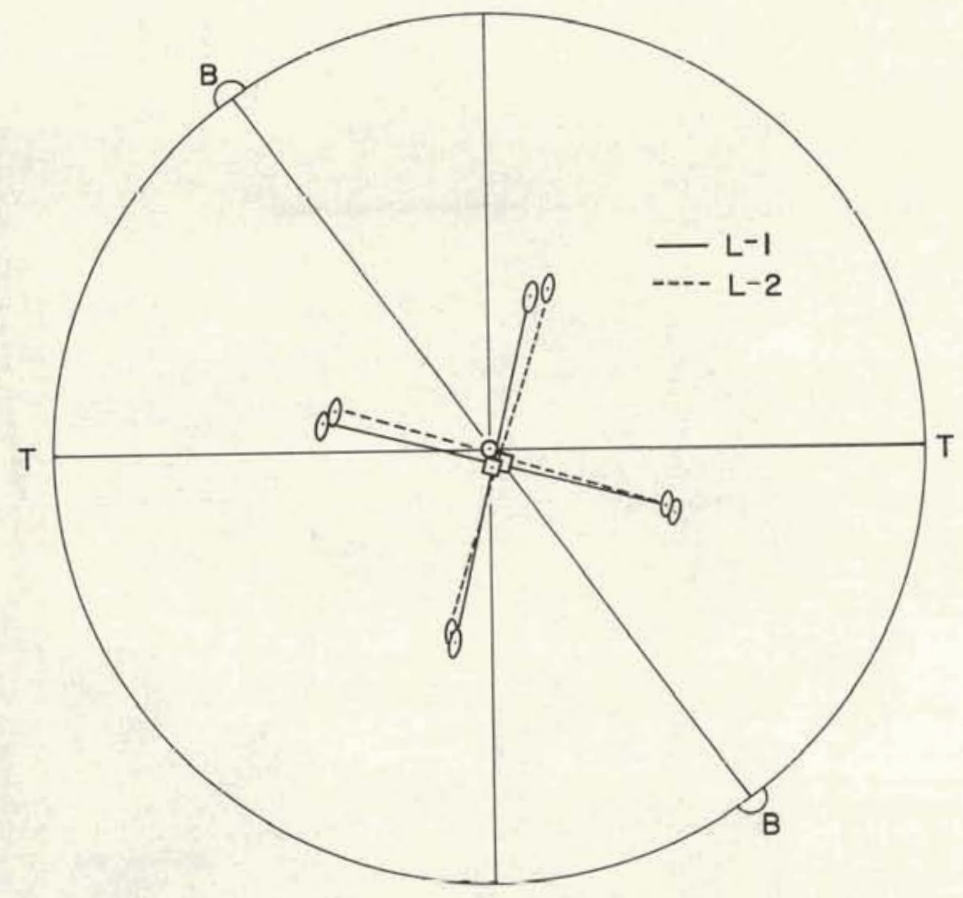

MU. 28305

Fig. 22B. Stereographic projection of deformed grains L-1 and L-2. 


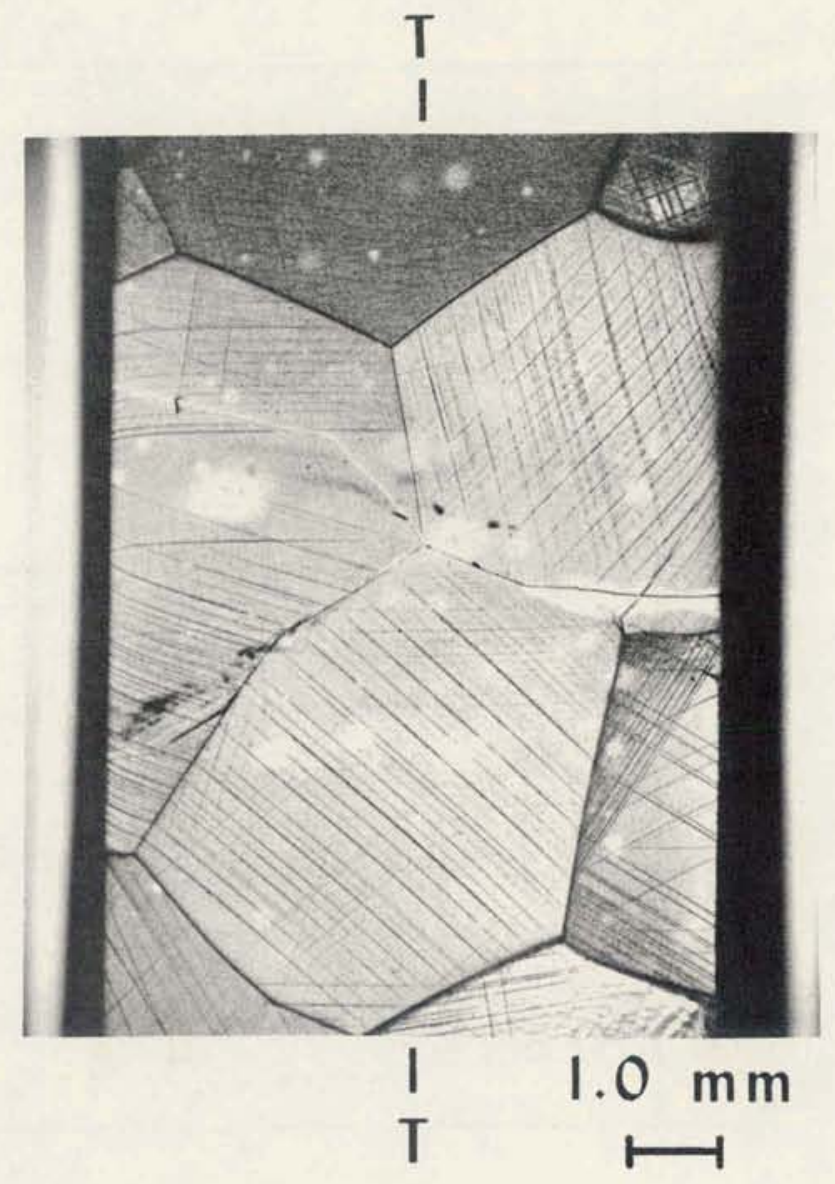

$\mathrm{ZN}-3354$

Fig. 23A. Slip and fracture in specimen $\mathrm{H}$. 


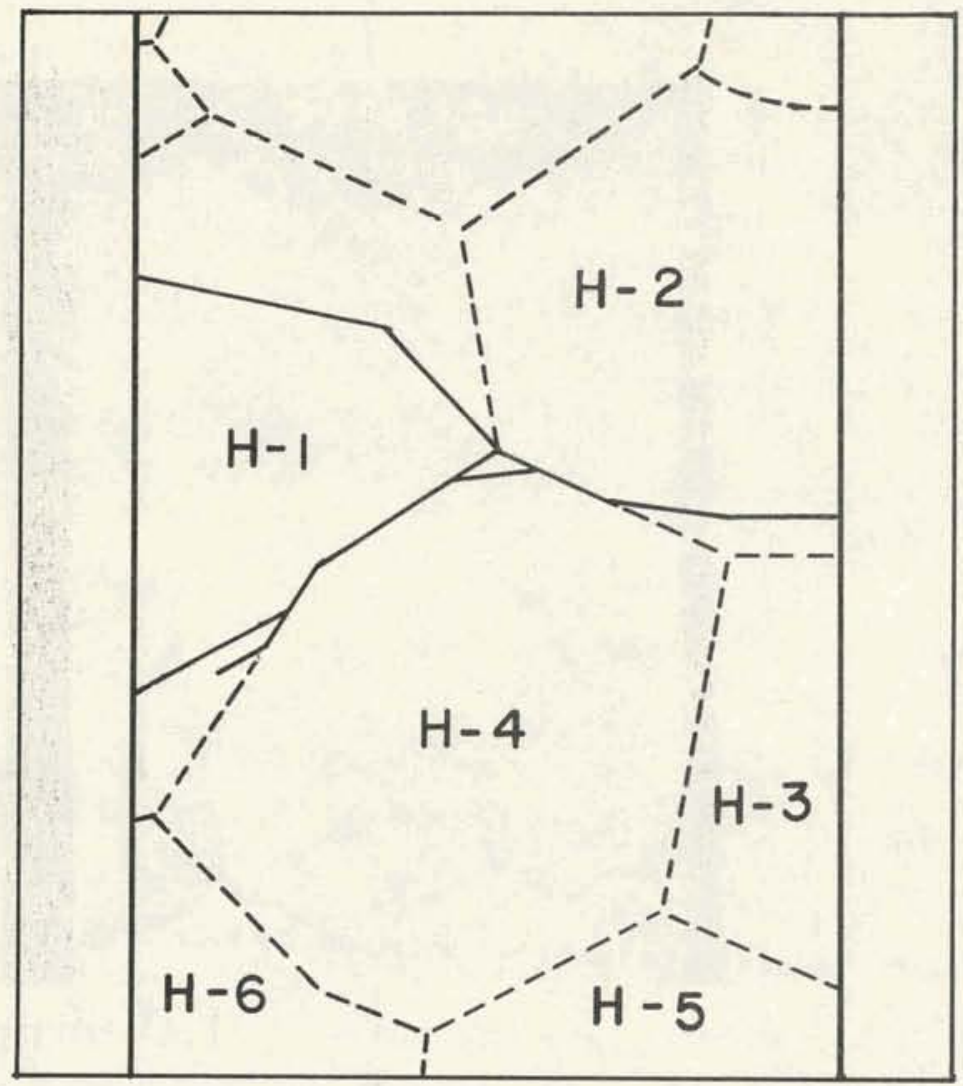

MU.28201

Fig. 23B. Identification of grains in specimen H. Misorientations between grains: $\mathrm{H}-\mathrm{l}$ and $\mathrm{H}-4,33 \mathrm{deg}$ twist and 45 deg tilt; $\mathrm{H}-2$ and $\mathrm{H}-4,14$ deg twist and 31 deg tilt; $\mathrm{H}-3$ and $\mathrm{H}-4,29$ deg twist and 22 deg tilt. 


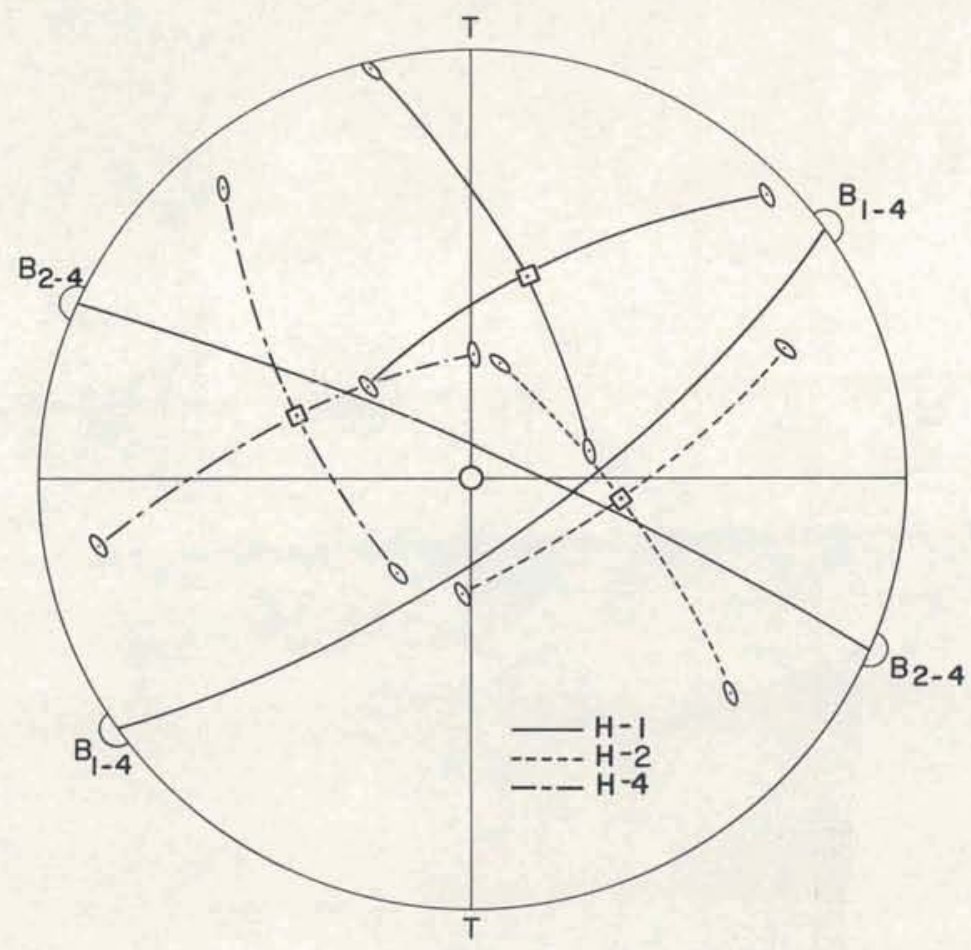

MU. 28308

Fig. 23C. Stereographic projection, grains $\mathrm{H}-1, \mathrm{H}-2, \mathrm{H}-4$ (see Figs. 23A-B). 


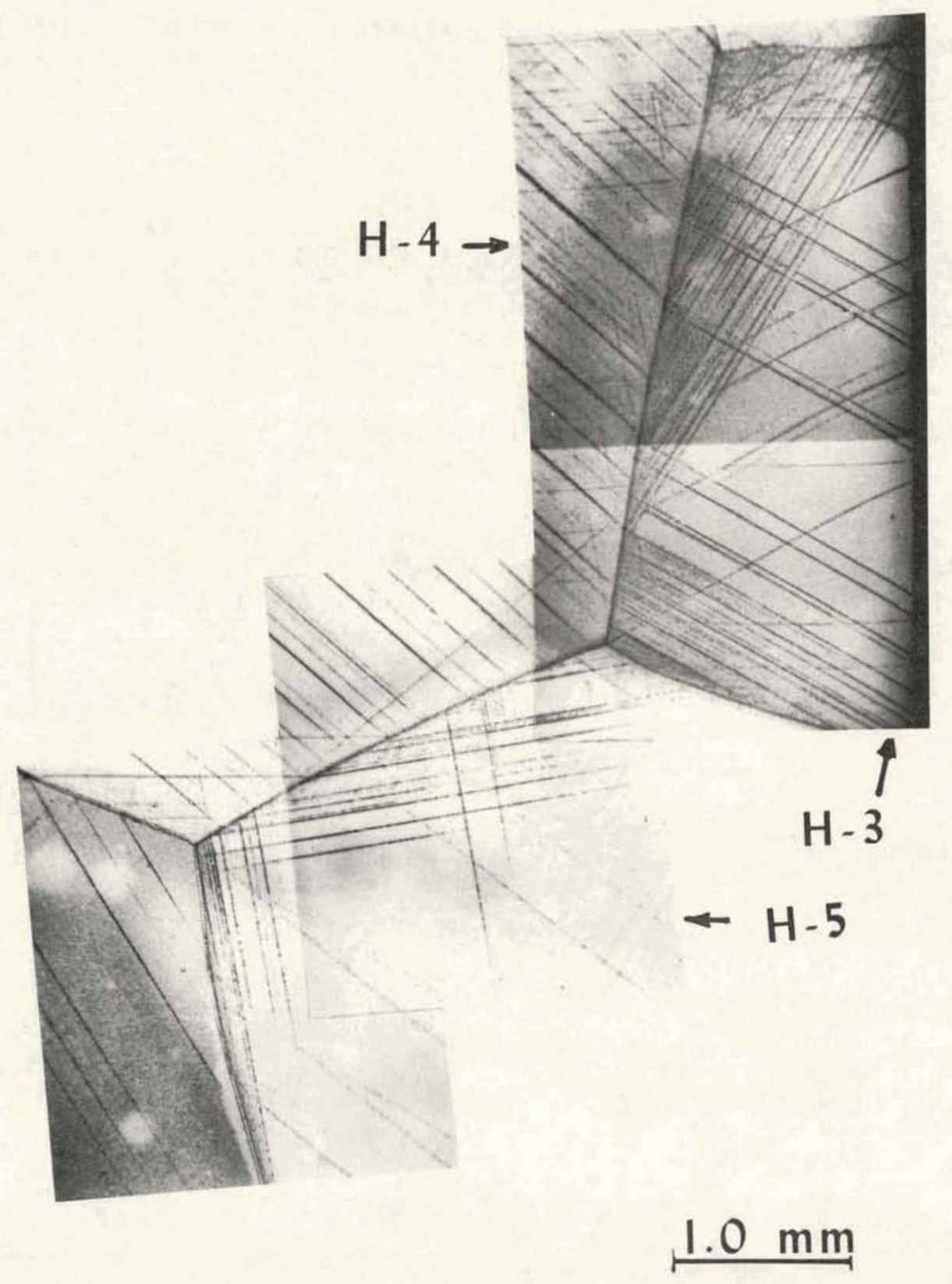

$\mathrm{ZN}-3355$

Fig. 24A. Slip lines at a grain boundary on the tension surface of specimen $\mathrm{H}_{\text {. }}$ Specimen axis is vertical. Transmitted light, $23 \mathrm{X}$. 


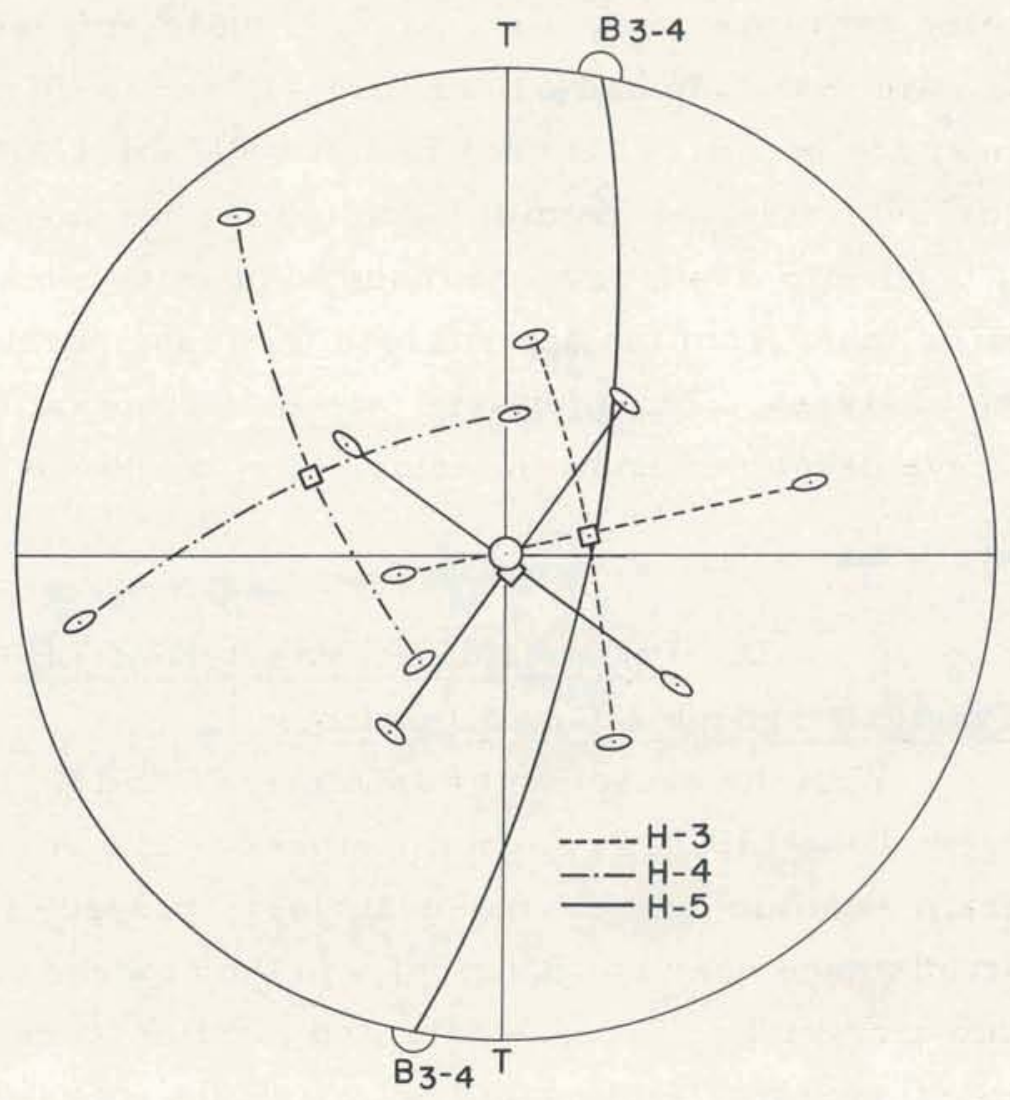

$M U .28306$

Fig. 24B. Stereographic projection, grains $\mathrm{H}-3, \mathrm{H}-4, \mathrm{H}-5$ (see Fig. 24A). 
$\mathrm{H}-4$ and $\mathrm{H}-5$ is of almost pure edge-type and was also accommodating deformation in $\mathrm{H}-4$. The resolved shear stress from the applied load on the latter two systems (H-5, 1, 2, Table II) was $368 \mathrm{psi}$. Slip of the type present in the curve of the boundary of $\mathrm{H}-5$ was rather common in several specimens.

There were several examples of small local slip systems operating with extremely low resolved-shear stresses. The fine horizontal slip at the top and bottom of $\mathrm{H}-4$, and the light vertiral slip in $\mathrm{H}-4$ near the boundary between $\mathrm{H}-4$ and $\mathrm{H}-3$ (H-4, 3, 4, Table II) had resolved-shear stresses from the applied load of only 205 psi. Thus, small local slip systems were made to operate although the resolved stress on them from the applied load was considerably below the critical yield stress. The additional stress for operation of these systems must have developed from the interaction of deforming grains in the aggregate.

\section{Fracture of Polycrystalline LiF}

\section{Fracture through 3-Grain Junctions}

With the exception of specimens I and K, all the fractures of polycrystalline LiF had common features. The fracture went through a 3-grain junction on the tension surface, passed along a boundary for a short distance near the junction, and then moved out of the boundary and into a crystal. The boundary and junction were in the center of the specimen, and the fracture did not originate at a boundary at the outside edge of the specimen.

Typical examples of fractures through 3-grain junctions may be seen in Figs. 16, 23 A and 25. In the case of specimen H (Figs. $23 \mathrm{~A}-\mathrm{C})$, the fracture probably originated at the boundary near the 3grain junction. Because of the large overall deformation of $\mathrm{H}-4$, the region of $\mathrm{H}-4$ near the 3 -grain junction was highly stressed. This condition is indicated by the existence of the horizontal slip operating in this area at a resolved stress from the applied load of only 205 psi. 


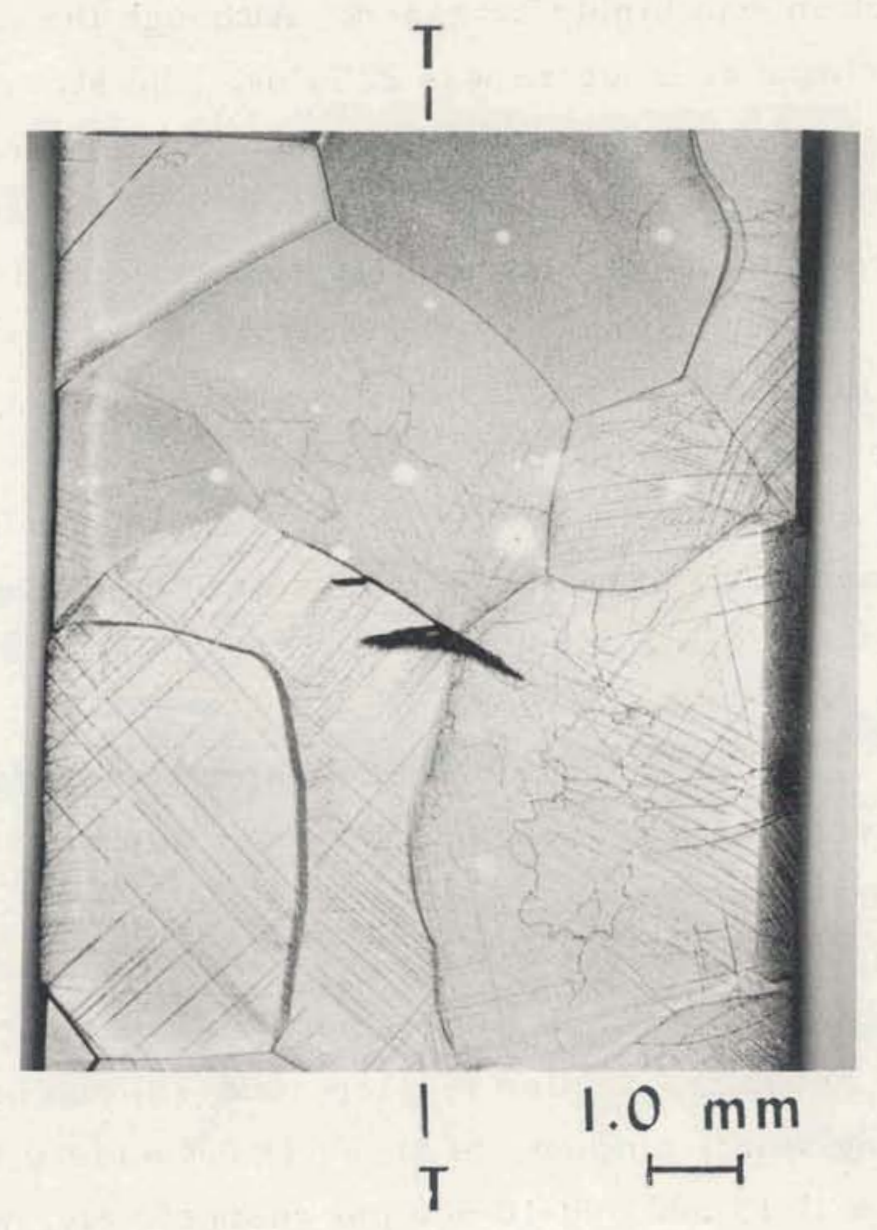

$\mathrm{ZN}-3356$

Fig. 25. Incomplete fracture in the tension surface of specimen $F$. 
The fracture path branched in two near the junction. One path followed the boundary and the other path cut transgranularly across the tip of H-4. This behavior also indicates that the part of H-4 near the apex of the junction was highly stressed. Although the macroscopic stress on the specimen at fracture was $2280 \mathrm{psi}$, the stress on the major slip system in $\mathrm{H}-2$, running into the boundary between $\mathrm{H}-2$ and $\mathrm{H}-4$, was only $593 \mathrm{psi}$. The fracture may have been nucleated at this boundary by a Stroh mechanism, when this slip system yielded.

Nabarro has pointed out that because slip (in metals) occurs only in discrete bands with a spacing of $10^{-4} \mathrm{~cm}$, there must be a region about $10^{-4} \mathrm{~cm}$ thick at a grain boundary where coherence of the grains causes severe elastic distortion and slip on unfavorable planes. 33 Accommodation of the large blocks of long-range slip present in this polycrystalline LiF must also result in elastic distortion and high boundary stresses.

Although fractures originated at boundaries and followed a boundary for at least a short distance, this effect is thought to be a result of high boundary stresses rather than inherent boundary weakness. This conclusion is based on two observations: (a) fractures often moved out of boundaries even though the boundaries were still suitably oriented for fracture under the applied tension, and (b) two polycrystalline specimens containing small amounts of $\mathrm{MgF}_{2}(<0.2$ and $<0.5 \%)$ failed with violent fractures at 13300 and 10500 psi respectively, with no apparent plastic flow. The boundaries in these specimens withstood stresses four to five times the fracture stress obtained with pure LiF. Assuming that the $\mathrm{MgF}_{2}$ did not have a large effect on the strength of the boundaries, then the low fracture stress of pure LiF cannot be attributed to inherently weak boundaries. It is of interest to note that the fracture strength of the doped specimens was in the same range as the yield stress $(\approx 14000$ psi) reported by Nadeau and Washburn for single crystals of LiF doped with about $0.2 \% \mathrm{MgF}_{2}{ }^{6}$ A direct comparison is difficult because the hardening effect of this impurity is extremely sensitive to heat treatment. However, even in these strong, and apparently brittle, polycrys talline specimens, some localized plastic deformation may have been 
necessary to initiate fracture.

2. Fracture in the Slip Plane

Figure 26A is a photomicrograph of the fracture in specimen $\mathrm{K}$ as seen from the side of the specimen. The specimen axis is horizontal, and the tension surface is at the bottom of the picture. A grain boundary runs from top to bottom in the right half of the picture. The plane of the crack in the left grain is nearly perpendicular to the plane of the picture, and the crack did not intersect the grain boundary on the tension surface. The dark areas in Fig. 26A are shadows caused by the fracture surface. The orientations of the two grains are shown in Fig. 26B. The orientation of the left grain was close to the usual orientation for cleaved single crystals. The slip system operating in the left grain was (110)[1ㅣㅣ, and the etched traces parallel to the fracture are almost pure edge bands.

It is thought that the fracture nucleated by dislocation pile-up at the grain boundary. However, the fracture nucleated, or at least propagated, in the slip plane rather than perpendicular to it as predicted by the Stroh theory. The possibility of this type of fracture in the slip plane was first suggested by Bullough (see reference 34 ), and is similar to the fractures of zinc as observed by Gilman. 17 


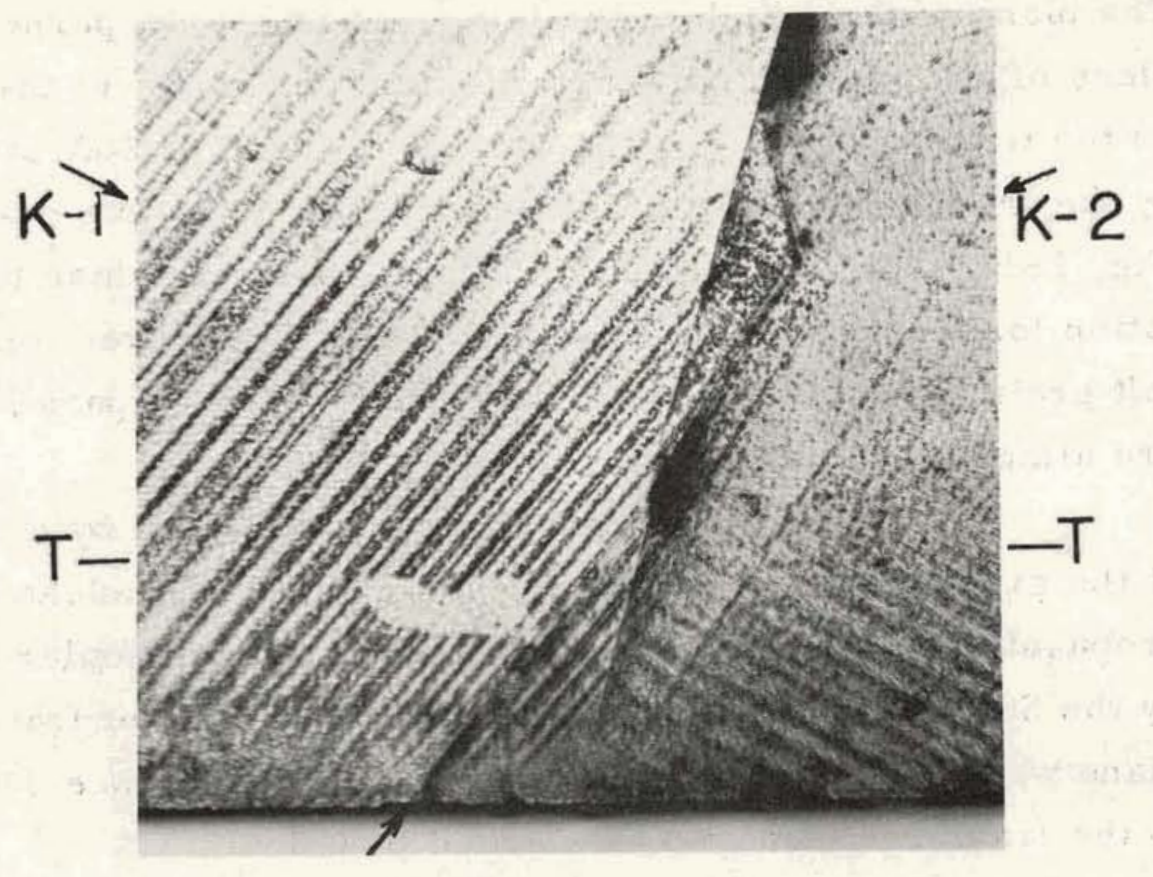

$\mathrm{ZN}-3372$

Fig. 26A. Photomicrograph of fracture in specimen K, as seen from the side of the specimen. 


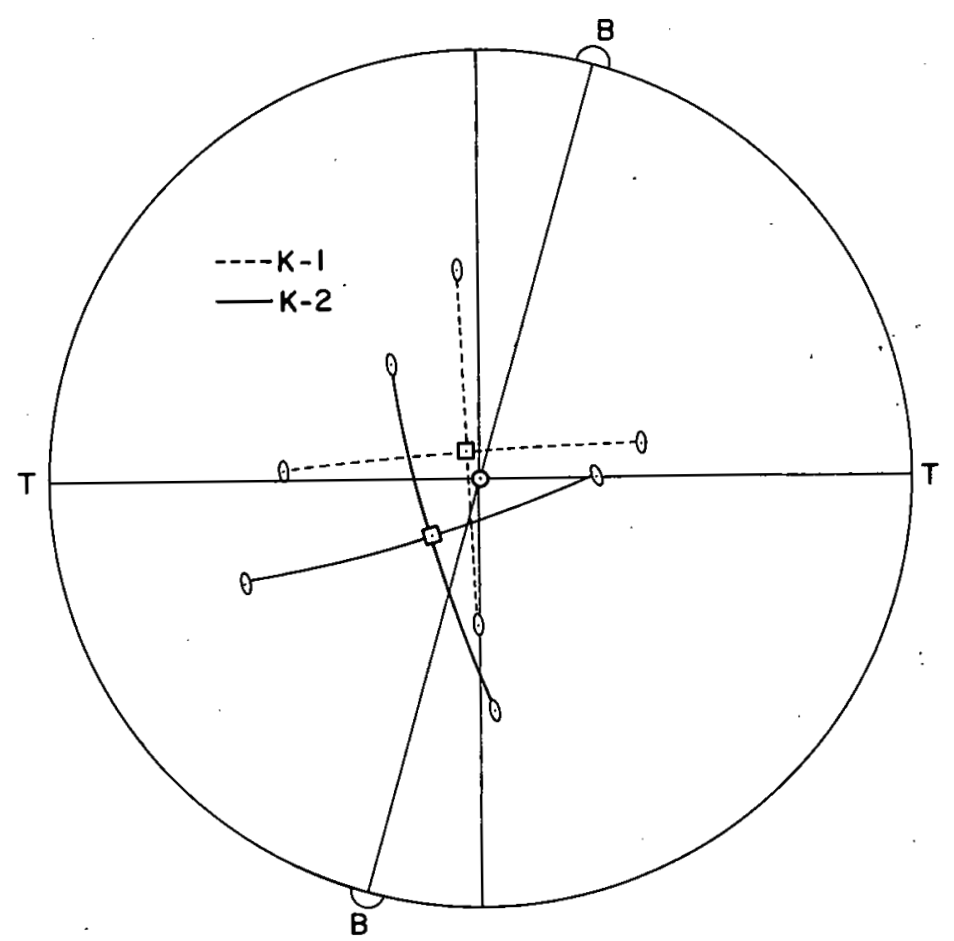

MU. 28307

Fig. 26B. Stereographic projection of orientations of grains $\mathrm{K}-1$ and $\mathrm{K}-2$ (see Fig. 26A). 


\section{DISCUSSION OF RESULTS}

\section{A. Plastic Flow and Fracture}

The marked influence of crystal orientation on the shape of the macroscopic stress-strain curve of LiF was demonstrated with single crystals. Polycrystalline specimens consisted of many crystals with various orientations. Favorably oriented grains deformed first under the applied stress, but their deformation was hindered by unfavorably oriented neighbors which were not deforming as readily. The shape of the stress-strain curve was the result of the action of the applied stress on grains of various orientations and of the interaction of neighboring grains which maintained boundary contact during deformation. Hence, the resulting macroscopic stress-strain curve of a true polycrystalline specimen had little resemblance to a stress-strain curve of a favorably oriented single crystal.

It is of interest to note in this connection that, according to Eq. (7), a crystal with the cubic $\mathrm{NaCl}$ structure which is stressed in pure tension or compression in the $\langle 111\rangle$ direction has no resolved shear stress on a $\{110\}\langle 1 \overline{1} 0\rangle$ type of slip system. This fact is significant because at least one crystal in a polycrystalline aggregate would be expected to have this orientation and thus be unable to deform at all under the applied stress.

According to Taylor, at least five slip systems must operate to obtain plastic deformation with grain boundary continuity in a polycrystalline aggregate. 16 LiF has only six slip systems normally operative at room temperature, and the probability that five of these may be suitably oriented for deformation to occur in all crystals of an aggregate before fracture occurs is extremely remote. For example, in the ten grains listed in Table II, the number of operating systems were distributed as follows:

$\frac{\text { operating systems }}{3} \quad \cdots \frac{\text { grains }}{4}$


The limited number of available slip systems is thought to be the major factor limiting the ductility of polycrystalline Li F aggregates. Many of the observations of the present study regarding the marked decrease in ductility in going from single-crystal to polycrystal LiF may be related directly to the limited number of slip systems available in $\mathrm{LiF}$.

A number of theories relating grain size to the strength of polycrystals use a grain size parameter of $\mathrm{d}^{-1 / 2}$, where $\mathrm{d}$ is the average grain diameter. This parameter originates in the condition for crack nucleation at a blocked slip band, where the longest slip band is taken as the grain diameter. In this study, the grains were very large, with only a small variation in grain size among the specimens. There were many large slip bands present, and crack nucleation is probably not limited by the length of the slip bands within the grains.

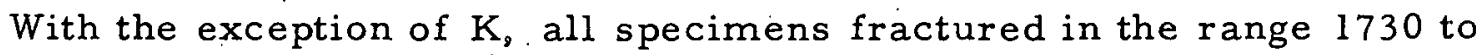
2460 psi, and no correlation between grain size and fracture stress was observed in the limited number of specimens tested. The fracture was probably initiated by some stress concentration, and the macroscopic fracture stress was only indirectly related to conditions existing at the origin of the fracture. Furthermore, the grain size in these samples was too large to give a true random distribution of stress concentrators and, therefore, some constant minimum fracture strength.

If the view is taken that the fracture stress in these largegrain samples was independent of grain size, then the shape of the polycrystalline stress-strain curves can be rationalized as follows. Grain boundaries were barriers to slip; so that specimens with smaller grains. had greater resistance to deformation. Because of the grain-boundary barriers, the stress in small-grain samples built up more quickly to the fracture stress, i.e., with less plastic deformation. Figure 27 shows the correlation obtained when the percent strain at fracture is plotted against the length of grain boundaries in the tension surface. (Measured by running a map distance-measuring device along the boundaries on a photographic enlargement similar to Fig。 16.) 


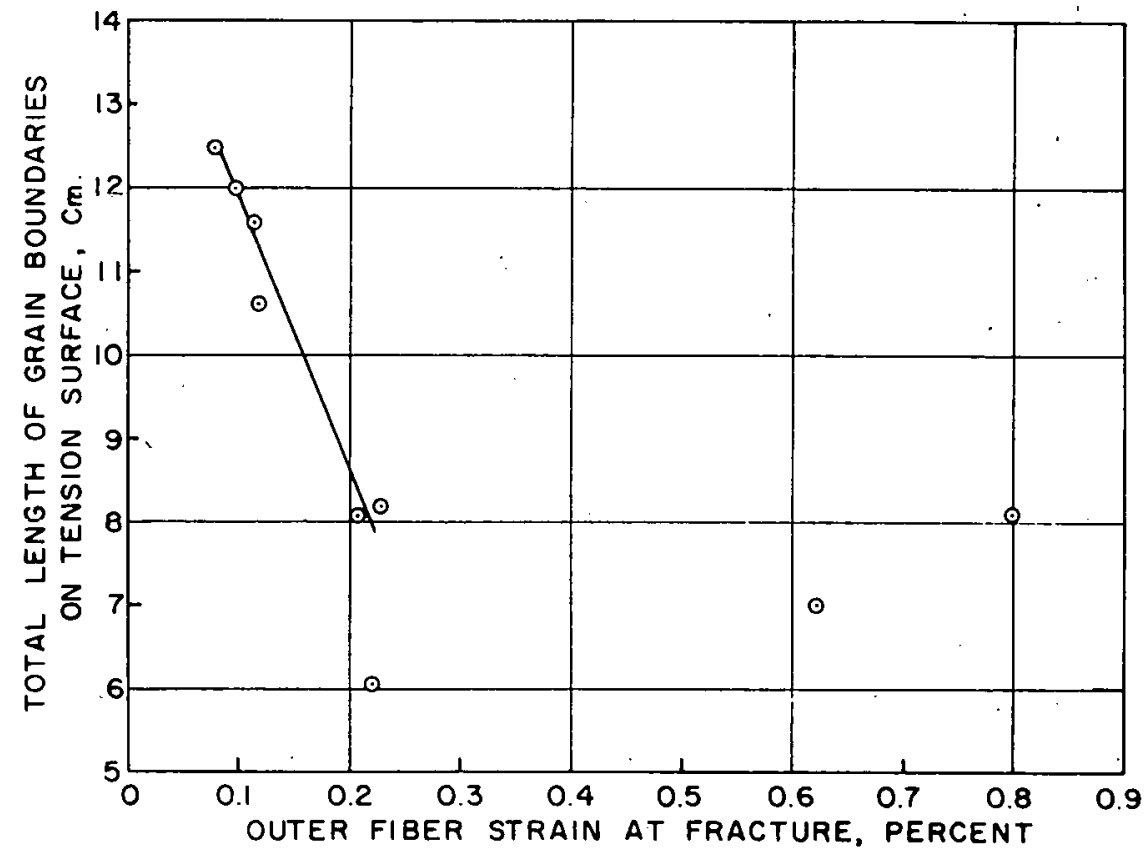

$M U-28301$

Fig. 27. Correlation of the length of grain boundary in the tension surface with the strain at fracture of polycrystalline LiF. 
With the exception of two very large grain specimens, $K$ and $L$, which underwent unusually large amounts of plastic deformation, the strain at fracture decreased with increasing boundary length. This grain size is not in the range $(<l \mu)$ where Parker predicted increasing ductility with decreasing grain size. ${ }^{34}$ This prediction, like the fracture theories, was based on the idea that the grain size would limit the length of the slip band that initiates fracture.

Grain boundaries were strong barriers to slip in the sense that slip from one grain was seldom propagated directly into a neighboring grain. This observation is consistent with the statement of Nye and others that the slip planes of two adjoining grains are not likely to meet in a line in a boundary. 21 However, the boundary contact was maintained during slip, and stresses resulting from slip in one grain were transmitted across the boundary into the neighboring grain. If a suitably oriented slip system was available, this second grain then deformed to accommodate the deformation in the first grain. This description is oversimplified because, in the general case, both grains were deforming under the applied stress at the same time as they were deforming locally to maintain boundary contact. Thus, two types of slip were operating that were only indirectly related to each other.

It is thought that the fractures associated with boundaries and 3-grain junctions were aided by boundary stresses. Some deformation occurred at the fractured boundary in every case. This was either deformation of neighboring grains under the applied stress, or deformation of one grainagainst a relatively undeformed neighboring grain. The cracks may have been nucleated by coalescence of edge dislocations by a Stroh mechanism. Stroh developed his theory on the basis of a pile-up of a single band, or several closely spaced bands, against a simple boundary. It has been shown that 3-grain junctions were regions of high residual stresses, and it is probable that such areas were preferred sites for crack nucleation. The exact origin of fractures could not be determined. However, they, were at or near the 3 -grain junctions, and the fractures then generally followed the highly 
stressed boundary before moving out of the boundary onto a cleavage plane.

\section{B. Fracture in the Slip Plane}

As mentioned earlier, Deruyttere and Greenough, ${ }^{35}$ and Gilman 36 have developed quantitative theories for the development of cleavage cracks in the slip plane by blocked edge dislocations. This type of fracture was suggested for specirrien K (Fig, 26.A-B). Some physical properties of LiF used in the following calculations are summarized in Table IV, and conditions at fracture for specimen $K$ in Table V.

Gilman has calculated the fracture stress for a zinc crystal which was oriented with the basal plane almost 90 deg to the tension axis. He assumed a blocked dislocation pile-up containing $n$ dislocations acting as a single large dislocation with a Burger's vector equal to $n b$. The condition for fracture is that the relaxed elastic tensile and shear strain energy released when the crack is formed shallexceed the surface energy of the new crack. Gilman derives an equation for the number of dislocations necessary for the crack nucleation:

$$
\mathrm{n}=\frac{4 \gamma}{\mathrm{b} \sigma_{\mathrm{n}}}\left[\frac{E(i-\nu)}{\mathrm{G}}\right]^{1 / 2} .
$$

From the values in Tables IV: and " $V$, we find $n$ equals 885 dislocations. The shear stress $\tau$, necessary to hold this number of blocked dislocations on a slip band of length $L$, was then calculated by using the formula

$$
\tau=\frac{3 G n b}{2 \pi L}
$$

In this.case, the slip-band length $L$ was taken as the length of the slip band that ultimately fractured, i. e., the distance along the fracture from the tension surface to the grain boundary, as seen in Fig. 26A-B. This gives the stress necessary to hold 885 dislocations on 
Table IV. Some physical properties of lithịm fluoride.

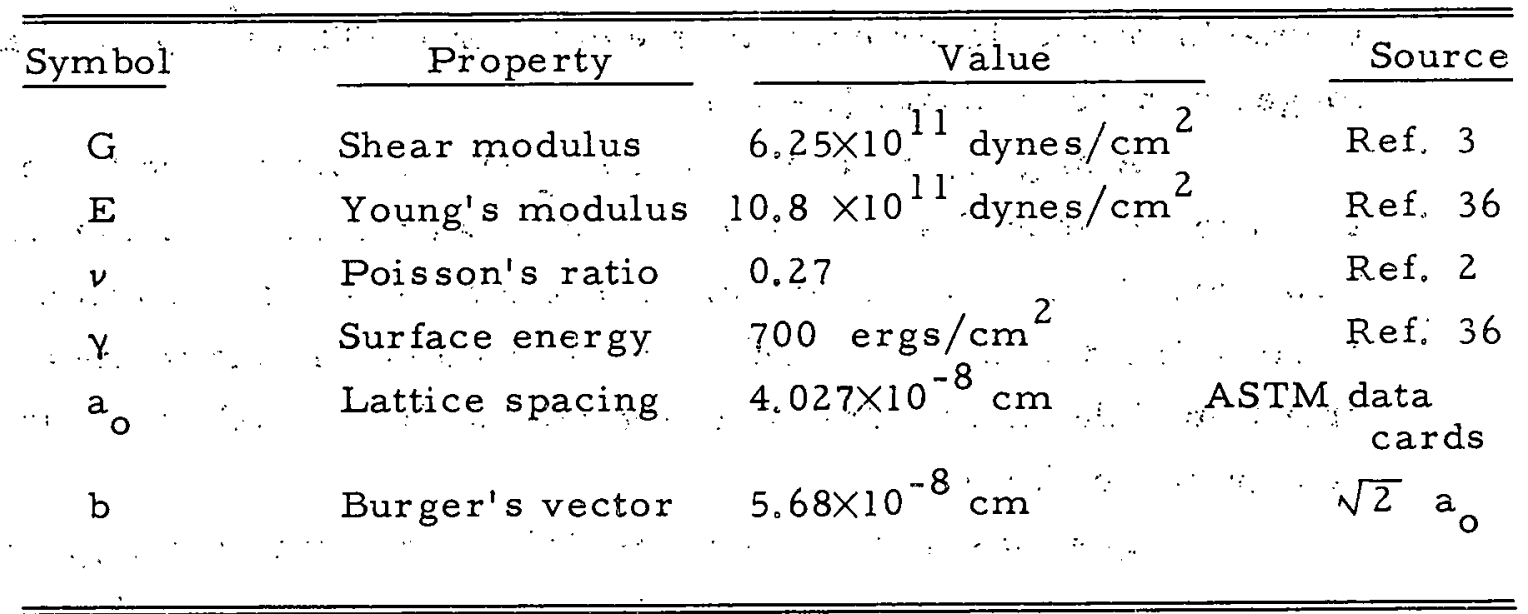

Table V. Fracture conditions for specimen $\mathrm{K}$.

\begin{tabular}{|c|c|c|}
\hline Symbol & Property & Value \\
\hline$\theta$. & $\begin{array}{l}\text { Angle between tension } \\
\text { axis and slip direction }\end{array}$ & $51 \mathrm{deg}$ \\
\hline$\lambda$ & $\begin{array}{l}\text { Angle betweeri tension axis } \\
\text { and slip plane normal }\end{array}$ & $39 \mathrm{deg}$ \\
\hline$\sigma$ & Outer-fiber stress at fracture & $\approx 10.6 \times 10^{7}$ dynes $/ \mathrm{cm}^{2}$ \\
\hline$\sigma_{\mathrm{n}}$ & $\begin{array}{l}\text { Normal stress on the slip } \\
\text { plane at fracture }\end{array}$ & $\approx 6.25 \times 10^{7}$ dynes $/ \mathrm{cm}^{2}$ \\
\hline$\sigma_{\mathbf{s}}$ & $\begin{array}{l}\text { Resolved shear'stress at } \\
\text { fracture }\end{array}$ & $\begin{array}{c}\approx 5.18 \times 10^{7} \text { dynes } / \mathrm{cm}^{2} \\
\because\end{array}$ \\
\hline L & $\begin{array}{l}\text { Length of slip band-taken here } \\
\text { as the crack length from the } \\
\text { tension surface to the grain } \\
\text { boundary. }\end{array}$ & $3.57 \times 10^{-2} \mathrm{~cm}$ \\
\hline
\end{tabular}


L as $\approx 43 \times 10^{4} \mathrm{~g} / \mathrm{cm}^{2}$. The discrepancy in numbers arises from Gilman's much higher normal stress for zinc $\left(32 \times 10^{4} \mathrm{~g} / \mathrm{cm}^{2}\right)$ and longer slip band length $(0.4 \mathrm{~cm})$ 。

A slightly different approach by Deruyttere and Greenough also uses a blocked array on a slip plane as the fracture source. 35 However, their condition for crack nucleation is that a crack of length equal to the distance between the first two dislocations in the array opens up if the elastic energy of the dislocations equals the surface energy of the crack。

The maximum number of dislocations that can be placed on a.slip plane of length $L$ is given by Eshelby, Frank, and Nabarro 37 as

$$
\mathrm{n}=\frac{\pi \mathrm{L} \sigma_{\mathrm{s}} \mathrm{k}}{\mathrm{Gb}}
$$

where $k=(1-v)$. For the shear stress and crack length of this sample, we find $n=119$ dislocations. The distance $x_{0}$ between the first two dislocations in a pile-up is

$$
x_{0}=\frac{1.84 G^{2} b^{2}}{2 \pi^{2} L \sigma_{s}^{2} k^{2}}
$$

The condition for crack initiation is that the dislocation elastic strain energy be equal to the surface energy of a crack of this length, so

$$
\sigma_{s}^{2}=\frac{1.84 \mathrm{G}^{2} \mathrm{~b}^{2}}{4 \pi^{2} \mathrm{Bk}^{2} \mathrm{~L}} \cdot 2 y .
$$

In Eq. (12), B is the elastic strain energy of an edge dislocation and is given by 27

$$
\mathrm{B} \approx \frac{16 \mathrm{~Gb}^{2}}{4 \pi \mathrm{k}}
$$


Deruyttere and Greenough.'s expression (Eq. 12) is simplified if the right side of Eq. (13) is substituted for $B$ so that the condition for crack nucleation becomes

$$
\sigma_{s}^{2}=\frac{1.84 \mathrm{G} \gamma}{8 \pi \mathrm{kL}}
$$

The shear stress calculated from this equation is $3.5 \times 10^{4} \mathrm{~g} / \mathrm{cm}^{2}$, which compares favorably with the actual resolved shear stress of $5.18 \times 10^{4} \mathrm{~g} / \mathrm{cm}^{2}$.

The stress gradient in the bend test specimen.was neglected in this calculation. The error was not large, and the corrected.stress at the head of the pile-up at the boundary was $4.85 \times 10^{4}$.vs the value $5.18 \times 10^{4} \mathrm{~g} / \mathrm{cm}^{2}$ that was used.

The single instance cannot, of course, be considered a verification of this formula. It is of interest to note that the condition for fracture given in Eq. (14) has, like other fracture-criteria, formulae, a fracture stress dependence on $\mathrm{L}^{-1 / 2}$. 


\section{SUMMARYY AND CONCLUSIONS}

(1) Techniques for forming polycrystal: LiF from the melt and for fabricating polycrystalline test specimens were developed and evaluated using single-crystal $\mathrm{LiF}$ as a control.

(2) The shape of single-crystal stress-strain curves was found to depend on modes of sample preparation and crystal orientation.

(3) Large-grain polycrystal.Li:F, ranging $1 *$ to $2: \mathrm{mm}$ in size, was tested in bending. Some plastic deformation was observed in all cases; and the outer fiber strain (elastic and plastic) ranged from 0.076 to $0.798 \%$ at fracture. The ductility of polycrystals was much less than that of single crystals.

(4) There was only a small variation in grain size among the : samples because of easy grain growth during anneal; no correlation between grain size and fracture stress wasthus evident. For the smaller-grain-size samples, the strain at fracture decreased with increase of total length of grain boundaries on tension:surface:

(5): An etch, consisting of $4 \% \mathrm{HBF}_{4}$ in. 190 proof ethyl alcohol, was developed.which revealed dislocation slip bands on all crystallographic faces of LiF. The deformation of polycrystalline LiF was investigated by using this etch.

(6) Plastic deformation was inhomogeneous among the grains of a polycrystalline aggregate. This inhomogeneity was attributed to differences in orientation of the grains with respect to the applied stress.

(7) Deformation was also inhomogeneous within individual grains as a result of interactions between grains. Boundary contact was maintained by local deformation near the boundary or by longrange secondary slip in neighboring grains.

(8) Local deformation along grain boundaries often occurred on slip. systems that had very low resolved-shear stresses from the applied load. The resolved-shear stresses were as much as 350 psi below the critical yield stress for the $\{110\}\langle 110\rangle$ system. In one case, 
wherein conditions were favorable for the development of a highly localized stressed condition without the development of a fracture, local boundary slip was observed on a (010)[101] plane.

(9) Three-gräin junctions were points of severe residual stresses, especially if local boundary deformation occurred along boundaries near the junction.

(10) Fractures originated at boundaries close to or at 3grain. junctions and traveled in the boundary before moving into a cleavage plane. Fractures were thus mixed, transgranular; and intergranular。

(11) Grain boundaries were not inherently weak, and they were often able to accommodate large amounts of local plastic flow. It is thought that fractures occurred at grain boundaries where stresses arising from deformation were not relieved by plastic flow. Because LiF has a limited number of slip systems available for plastic flow at room temperature, high local stresses were not always relieved by local deformation. These'observations are in general agreement with present theories on the interrelation of deformation and fracture.

At least two possibilities remain for enhancing the ductility of polycrystalline aggregates of materials with ductile properties similar to LiF. One is the suggestion by Parker that extremely. small grain size would prevent the development of high local stresses by limiting the length of slip bands within individual grains. 34 A second possibility is that, if the number of operating slip systems could be increased from 6 to 12 by somehow promoting easy slip on the system $\{100\}\langle 110\rangle$, then high local stresses might be more easily relieved by local plastic flow. This hypothesis is being tested by deforming polycrystalline $\mathrm{LiF}$ at temperatures above $400^{\circ} \mathrm{C}$, where this second system becomes easily active. 


\section{ACKNOW LEDGMENTS}

The author wishes to thank. Professor Joseph A. Pask, who was the thesis supervisor, and Professor Richard M. Fulrath for their advice and encouragement through the course of this research.

This work was done under Lle auspioos of the United States Atomic Energy Commission. 


\section{REFERENCES}

1. J. J. Gilman, Acta Met. 7, 608 (1959).

2. J. J. Gilman and W. G. Johnston, The Origin and Growth of Glide Bands in Lithium Fluoride Crystals, in Dislocations and Mechanical Properties of Crystals, edited by J. C. Fisher et al. (John Wiley \& Sons, Inc., New York, 1957) pp. 116-16l。

3. J。 J. Gilman, J。.Appl。 Phys, 30, 1584 (1959). Also, for a comprehensive review of the mechanical behavior of ionic crystals, see Gilman's recent article, Mechanical Behavior of Ionic Crystals, in Progress in Ceramic Science, Vol. I, edited by J。.E. Burke (Pergamon Press, New York, 1961), pp 146-199.

4. W. G. Johnston and J. J. Gilman, J. Appl. Phys. 31, 632 (1960).

5. W. G. Johnston and J. J. Gilman, J.Appl. Phys。30, 129 (1959).

6. J. Nadeau and J. Washburn, The Influence of Point Defects on the Mechanical Properties of Lithium Fluoride, Minerals Research Laboratory, University of California, Berkeley, Series No. 147, Issue No, 1, U。S.A.E。C. Contract No。AT(11-1)-34, Project 28 (Jan. 1960) 76 pp. (unpublished)。

7. A. R。C.Westwood, Phil. Mag。VIII, 5, 981 (1960).

8. R. J. Stokes, T。 L。 Johnston, and C. Ho Li, Phil。 Mag。VIII, 3 , 718 (1958).

9. R. J. Stokes, T. L. Johnston, and C. H. Li, Phil. Mag. VIII, 4, 137 (1959).

10. R. J. Stokes, T。 L. Johnston, and C。 Ho Li, Phil. Mag. VIII, 4, 920 (1959).

11. R. J. Stokes, T. L. Johnston, and C. H. Li, Phil. Mag. VIII, 6, 9 (1961).

12. J. Washburn, A. E. Gorum, and E. R. Parker, Trans. Met. Soc. AIME 215,230 (1959).

13. H. C. H. Carpenter and C. F. Elam, Proc.Roy. Soc.(London) A100, 329 (1921). 
14. H. W。 Paxton, M. A. Adams, and T。 B. Massalski, Phil。 Mag。 VII 43,257 (1952)。

15. W. Boas and M. E. Hârgreaves, Proc. Roy。 Soc. (London) A 193, 89 (1948).

16. G. I. Taylor, J. Instr: Met。 62, 307 (1938).

17... J. J。 Gilman, Trans。 Met。 Soc. AIME 212, 783 (1958)。

18. J. Do Mote and J.E. Dorn, Trans. Met。Soc。AIME 218, 491 (1960).

19. F. E. Hauser, C. D. Starr, L。 Tietz, and I. E. Dorn, Trans。 Am.: Soc。 Metals 47, 102 (1955).

20. F。 E. Hauser, $P_{\circ}$ R. Landon, and $J_{\circ} E_{0}$ Dorn, Trans。Am. Soc。 Metals 48,986 (1956).

21. J. F. Nye, Proc. Roy. Soc. (London) A 198, 190 (1949).

22. J. Jo Gilman, J. Appl。 Phys, 27, 1262 (1956)。

23. C. Zener, The Micro-Mechanism of Fracture, in Fracturing of Metals (American Society for Metals, Noveity, Ohio 1948), pp. 3-31。

24. A. N. Stroh; "A Theory of the Fracture of Metals," Advan. Phys。 6. 4128 (1957).

25. A.R.C.Westwood, Phil。Mag。VII 6, 195 (1961\%

26. W. Betteridge and A。W。 Franklin, J。Inst。 Metals 80, 147 $(1951-52)$.

27. A. $H_{0}$ Cottrell, Dislocations and Plastic Flow in Crystals (Oxford University Press, London, 1953.)

28. See R. S. Scheffee and J。 L。 Margrave; J。Chem, Phys, 31 , 1682 (1959), for references to original work on vaporization of LiF.

29. S. Timoshenko, Strength of Materials, Vol. I (D. van Nostrand Company Inc, Princeton, New Jersey, 1955), Chap. IV.

30. S. Timoshenko, Strength of Materials, Vol。II (D. van Nostrand Company Inc。, Princeton, New Jersey, 1956), Chap. IX. 
31. Smithsonian Physical Tables, 9th revised edition, edited by W. E. Forsythe (Smithsonian Institution, Washington, D. Co, 1954).

32. Personal communication from W. G. Johnston, Research.Department, General Electric Company, Schenectedy, New York.

33. F.R. N. Nabarro, Influence of Grain Boundaries on the Plastic Properties of Metals, in Some Recent Developments in Rheology (British Rheologists Club, 1950), pp. 38-52.

34...E. R. Parker, Fracture of Ceramic Materials in Fracture, edited by B. L. Auerbach et al. (John Wiley \& Sons, Inc。, New York, 1959), pp. 181-192.

35. A. Deruyttere and G. B. Greenough, J. Inst. Metals $\underline{84}, 337$ (1955-56)。

36. J. J. Gilman, "Cleavage, Ductility and Tenacity of Crystals," op. cit. reference 34, pp. $193-224$ 。

37. J. D. Eshelby, F.C. Frank, and F.R. N. Nabarro, Phil。 Mag. VII $\underline{42}, 351$ (1951). 
This report was prepared as an account of Government sponsored work. Neither the United States, nor the Commission, nor any person acting on behalf of the Commission:

A. Makes any warranty or representation, expressed or implied, with respect to the accuracy, completeness, or usefulness of the information contained in this report, or that the use of any information, apparatus, method, or process disclosed in this report may not infringe privately owned rights; or

B. Assumes any liabilities with respect to the use of, or for damages resulting from the use of any information, apparatus, method, or process disclosed in this report.

As used in the above, "person acting on behalf of the Commission" includes any employee or contractor of the Commission, or employee of such contractor, to the extent that such employee or contractor of the Commission, or employee of such contractor prepares, disseminates, or provides access to, any information pursuant to his employment or contract with the Commission, or his employment with such contractor. 